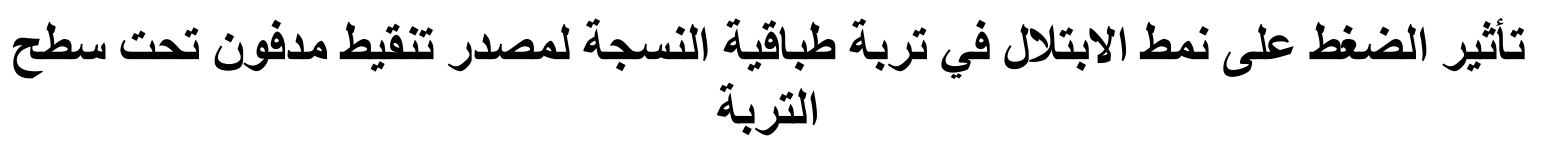

\author{
محمد طارق خليل \\ مدرس مساعد / موارد مائية ملئي \\ الكلية التقتية / قسم هندسة تقنيات الحاسوب / الموصل
}

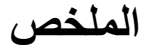

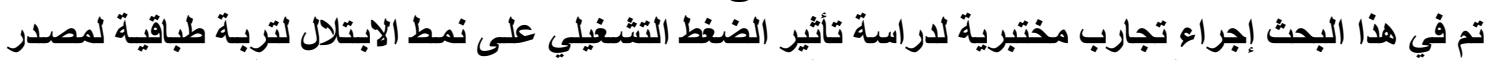

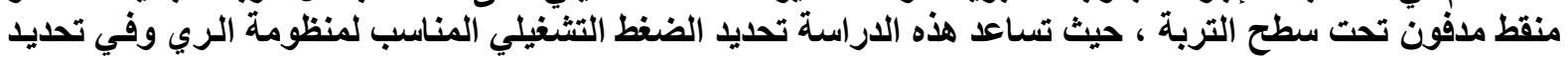

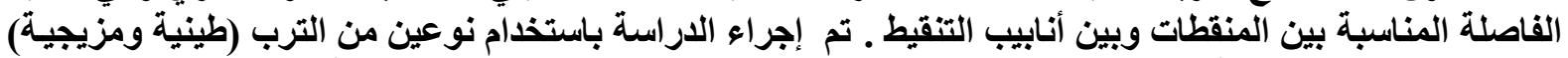

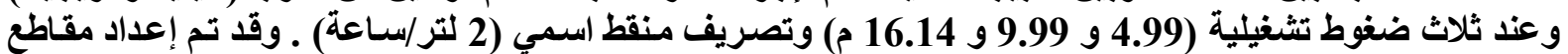

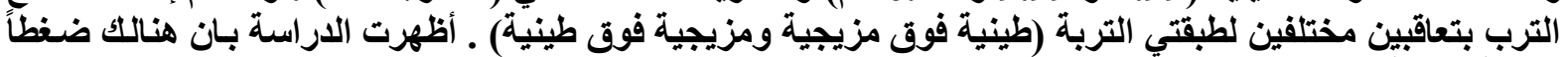

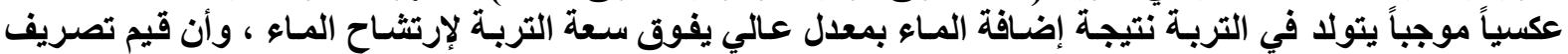

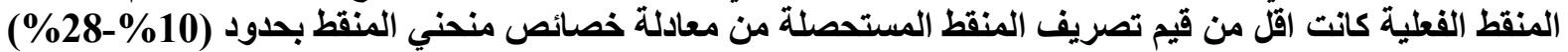

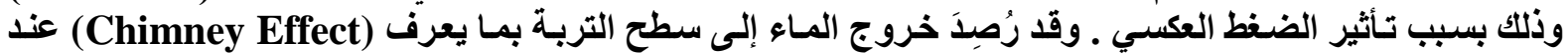

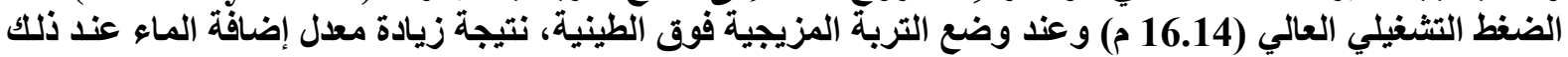

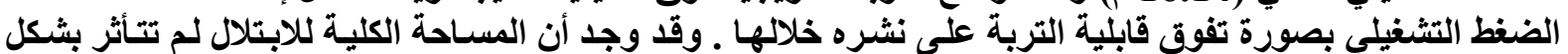

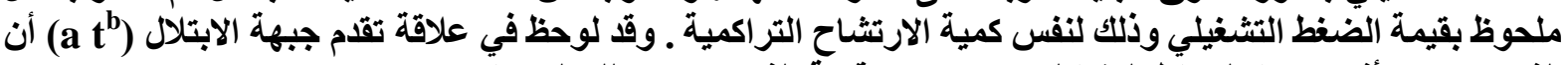

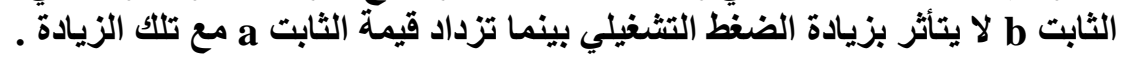

\title{
Pressure effect on wetting pattern in layered soil for subsurface point source \\ T.M. Khalil
}

Assistant lecturer / Water Resources

Technical College

\begin{abstract}
Laboratory experiments were carried out to investigate the effect of operating pressure on wetting pattern in layered soil for subsurface point water source. This study helps to determine a suitable operating pressure and appropriate spacing between emitters and drip lateral pipes. The layered soil profiles were prepared using two types of soil (clay and loam) in two combinations (clay over loam and loam over clay). Three operation pressures $(4.99,9.99$ and $16.14, \mathrm{~m})$ with a nominal dripper discharge rate $(2$ 1/hr) were used. The experimental results showed that positive back pressure around dripper outlet develops, when the water application rate is larger than the soil infiltration capacity, and the actual dripper discharges were less than the rated dripper discharges by about (10\%-28\%) due to back pressure effect . Furthermore, it has been observed that water start rising up to the soil surface (Chimney Effect) when the operating pressure is $(16.14 \mathrm{~m})$ for the loam over clay soil profile, which occurs when water application rate exceeds the soil capability to spread the water. It is found that the total wetted area for both layers was not affected by the operation pressure for the same volume of applied water. In the relationship of the wetting advance $\left(a t^{b}\right)$, it is found that, the constant (b) is not effected by operation pressure while the constant (a) increased with increased operation pressure .
\end{abstract}

Key Wards: Pressure wetting pattern, Subsurface Soil, Soil infiltration 


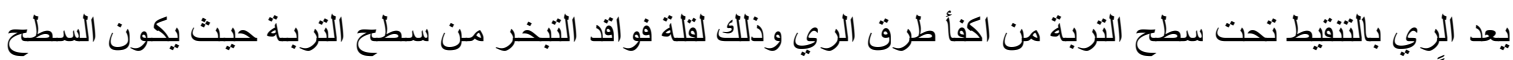

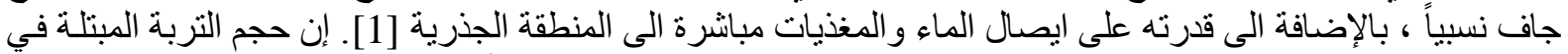

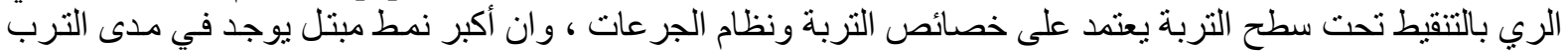

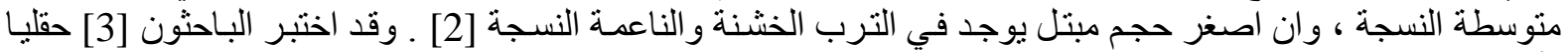

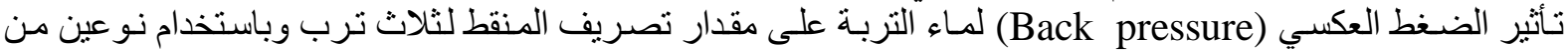

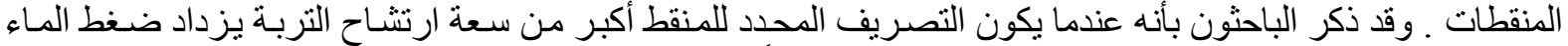

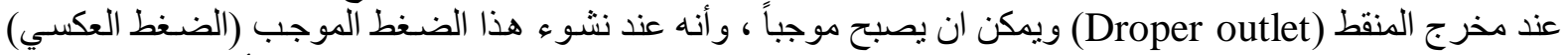

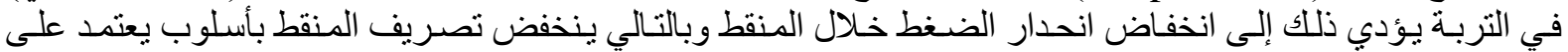

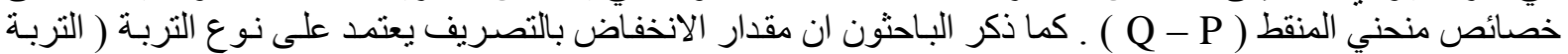

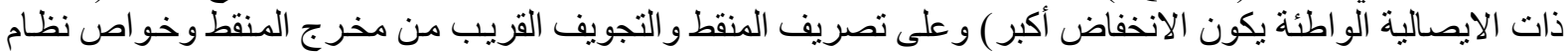

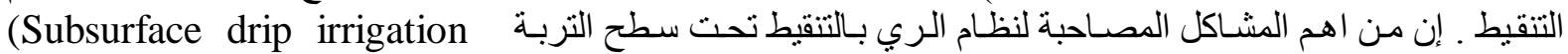

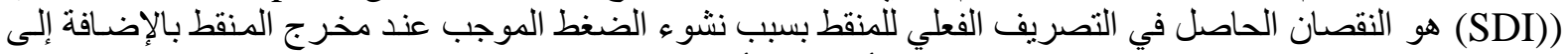

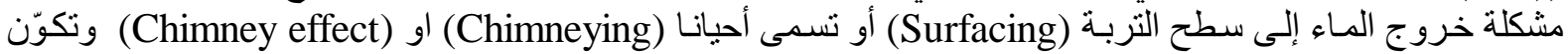

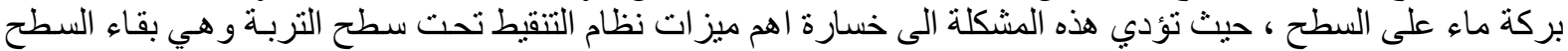

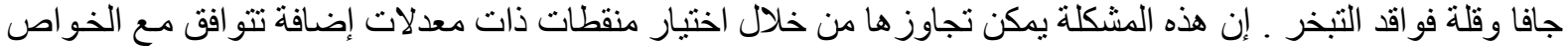

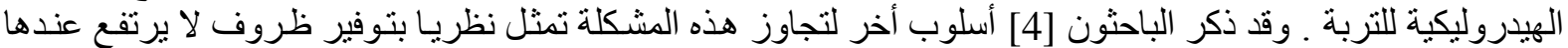

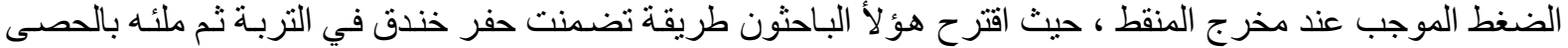

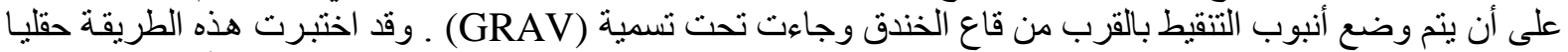

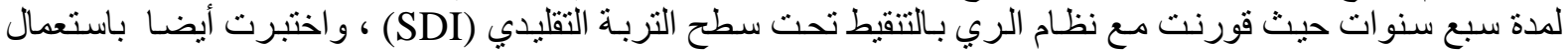

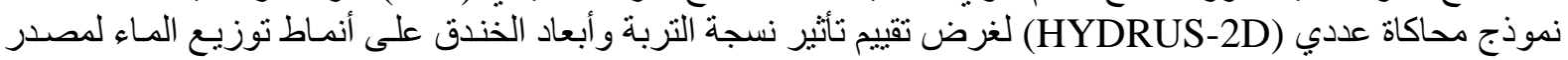

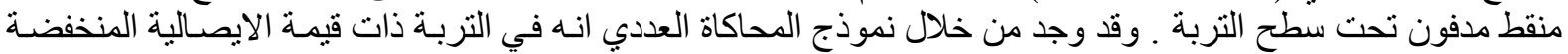

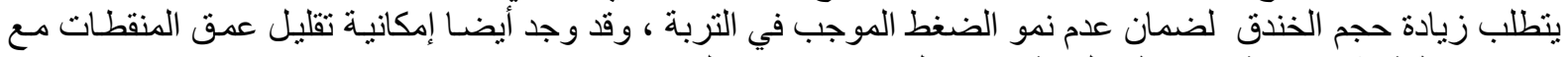

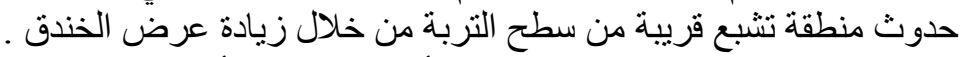

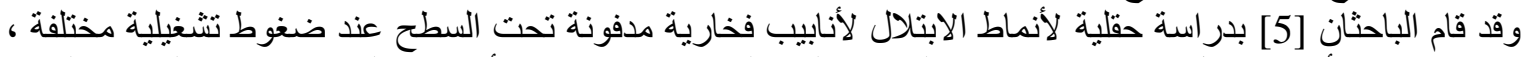

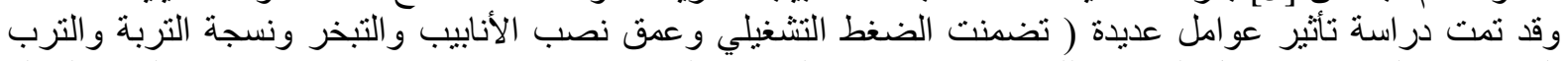

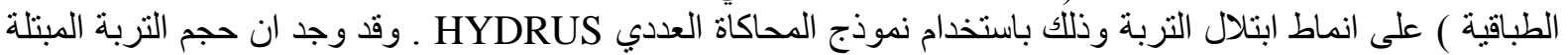

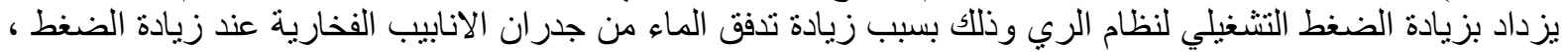

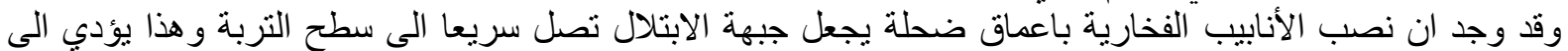
زيادة انتشار الماء أفقيا أي أن هناك علاقة عكسية بين عمق نصب الأنابيبي الفخارية والمسافة الجانبية الإنية بين هذه الأنابيب ،

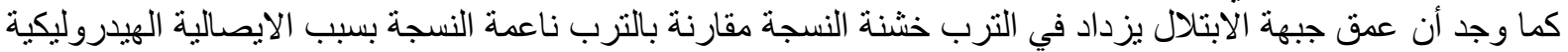

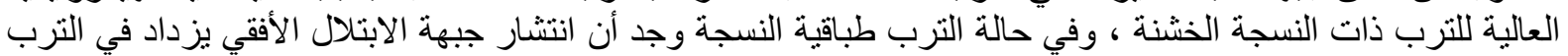

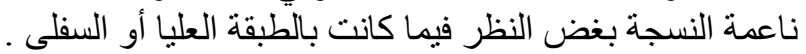

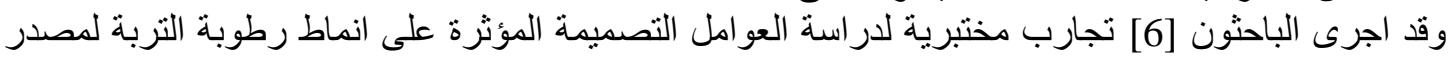

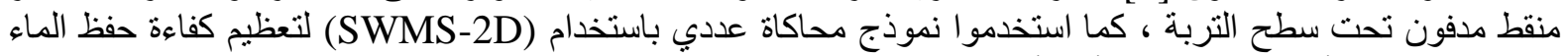

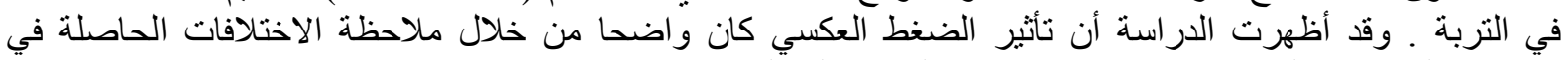

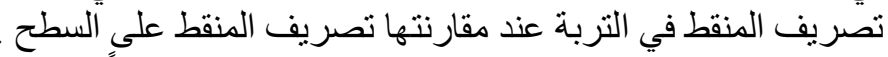

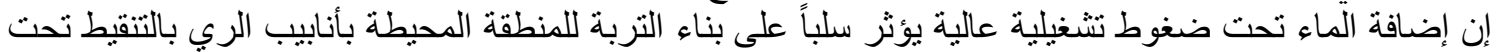

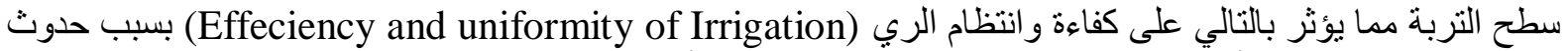

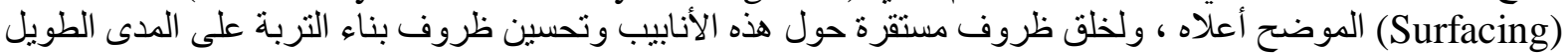

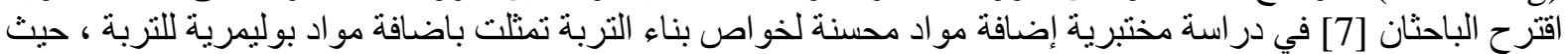

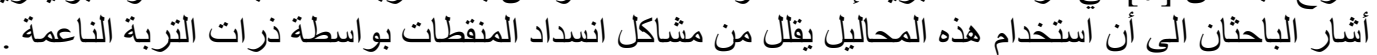

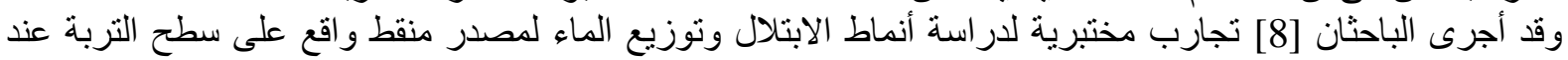

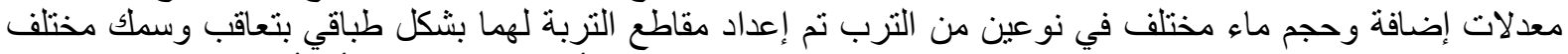

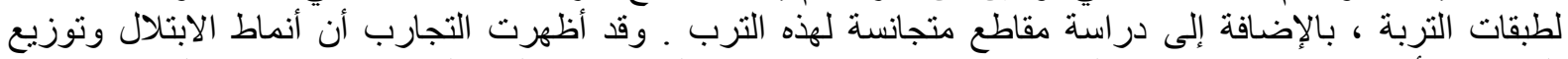

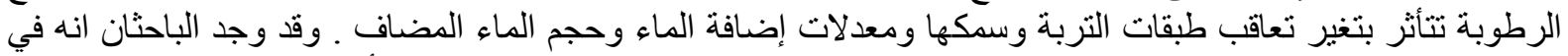

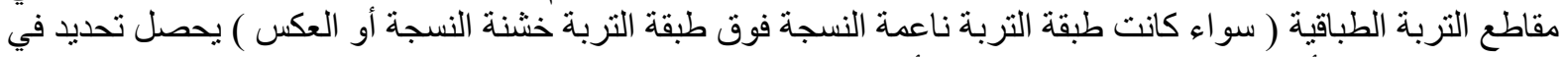

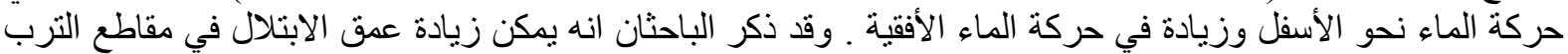

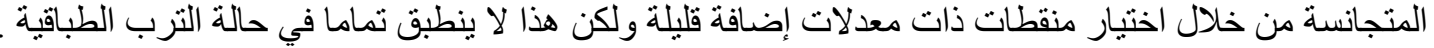


إن الهدف من هذا البحث هو دراسة تأثثير الضغط التشغيلي على أنماط ابتلال التربة لمقاطع تربة طباقية النسجة من

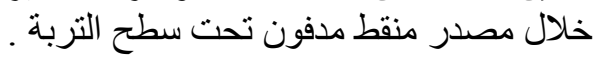

\section{طرق ومواد البحث}

أجريت التجارب المختبرية للبحث في مختبرات قسم البناء والإنشاءات / الكلية التقنية / الموصل ، خلال شهري نيسان وأيار لسنة 2011 .

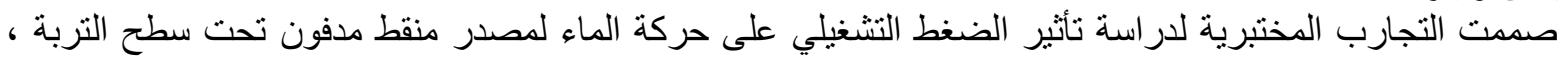

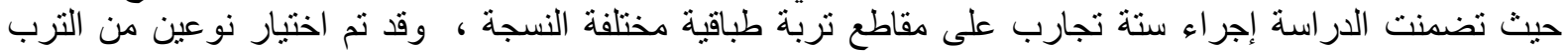

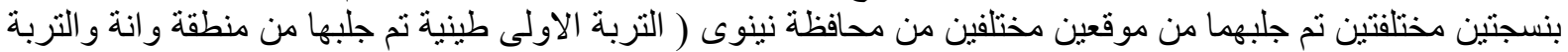

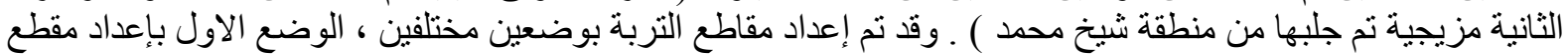

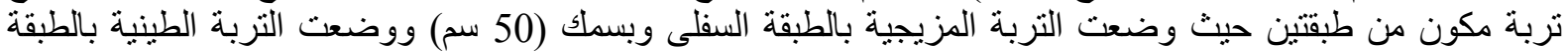

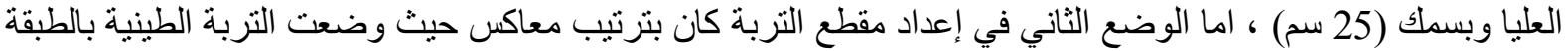

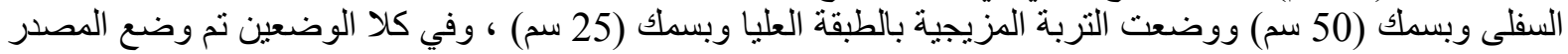

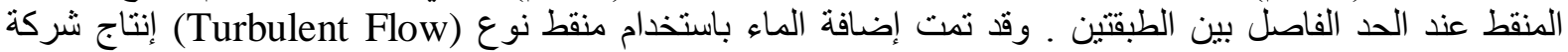
وبتصريف اسمي 2 لتر/ساعة و عند ثلاث ضغوط نوع تشغيلية وكما يلي : (Adritec Group International)
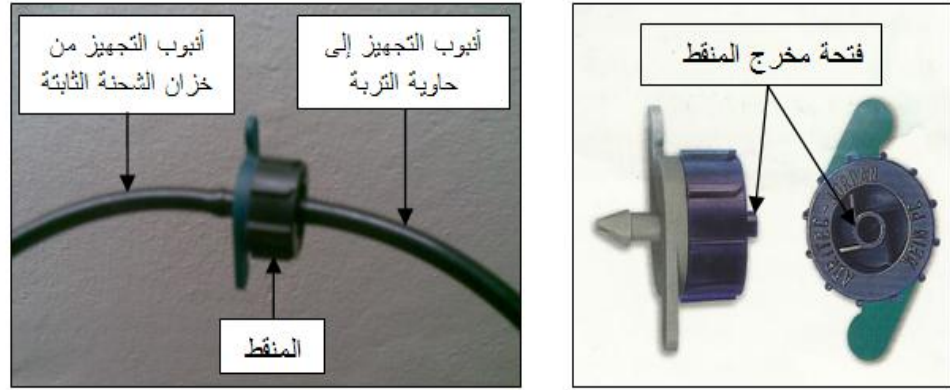

الثكل (1) يوضح المنقط و الأنبوبان البلاستيكيان المرتبطان فيه .

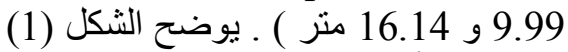
المنقط و الأنبوبان البلاستيكيان المرتبطان

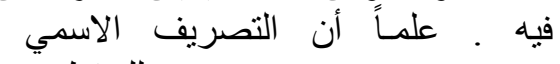
(Nominal discharge) التصريف الأولي (او التجاري) عند ضغط لإنطي

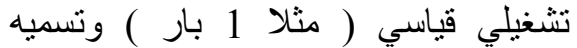

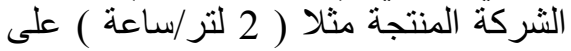

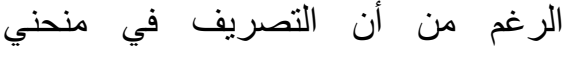
خصائص المنقط المثبت من قبل الثركة

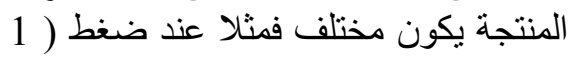

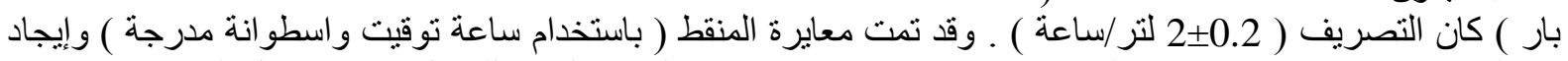

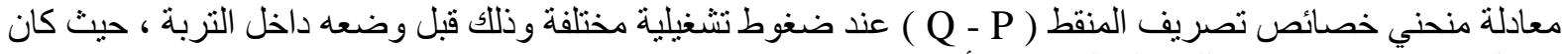
معامل الارنباط (0.992) للمعادلة الموضحة أدناه :

$\mathrm{Q}=2.271 \mathrm{P}^{0.541}$

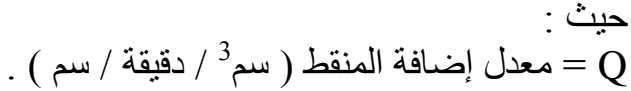

$$
\begin{aligned}
& \text { P = P }
\end{aligned}
$$

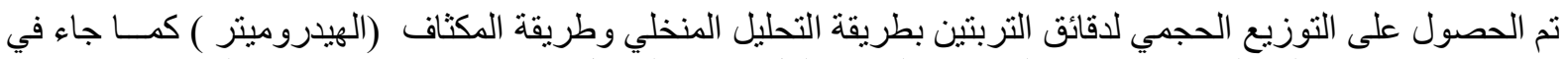
[9] وبالاستعانة بمثلث النسجة تم تحديد التصنيف النسجي لكل تربة ـ الجدول ( 1 ) يبين نسب مكونات التربتين .

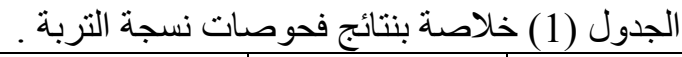

\begin{tabular}{|c|c|c|c|c|}
\hline تصنيف النسجة* & الطين غم/كغ & الغرين غم/كغ & الرمل غم/كغ & أسم المنطقة \\
\hline Clay ، طينية & 597 & 362.5 & 40.5 & و انة / نينوى \\
\hline مزيجية ، Loam & 247 & 425 & 328 & شيخ محمد/نينوى \\
\hline
\end{tabular}

تم تجفيف هاتين التربتين في الهواء ( air-dry ) ، حيث أصبح المحتوى الرطوبي الابتدائي الوزني (غم ماء/ كغم تربة)

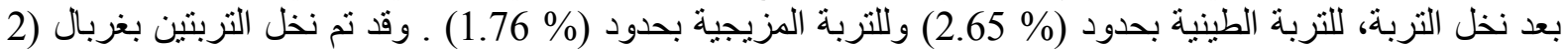
ملم × 2 ملم) . أجريت فحوصات الكثافة الظاهرية لكلا التربتين في الحقل باستخدام طريقة الأسطو انة القاطعة فكانت 
قيمتها ( 1.2 و 1.36 ، غم/سم³ ) للتربة الطينية والتربة المزيجية على التوالي ـ أجريت التجارب المختبرية باستخدام

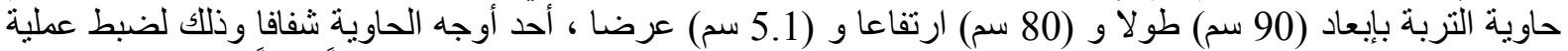

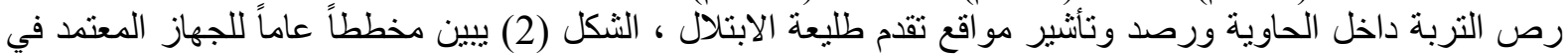

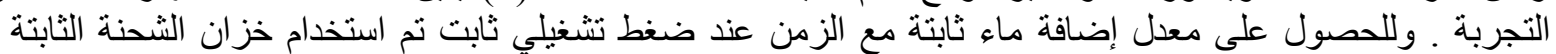

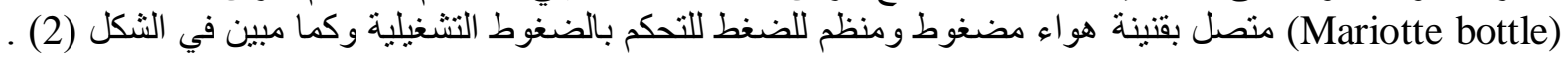

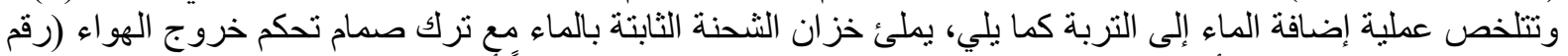

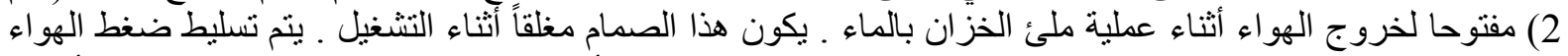

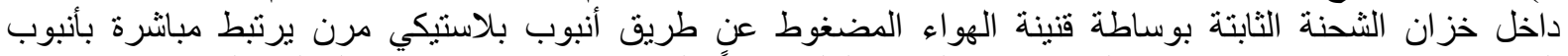

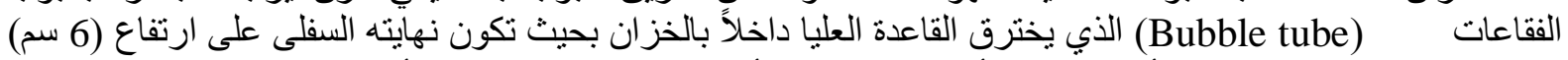

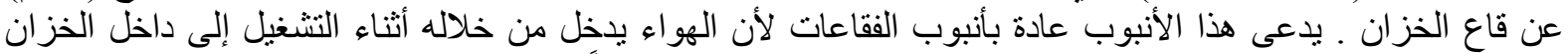

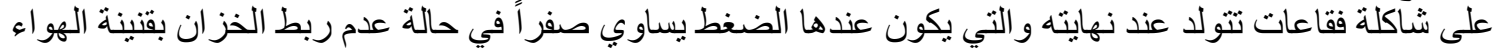

المضغوط ـ ويتم التحكم بمقدار الضغط المسلط باستخدام منظم للضغط يرتبط بقتينة الهواء المضغوط بشكل مبانشر ،

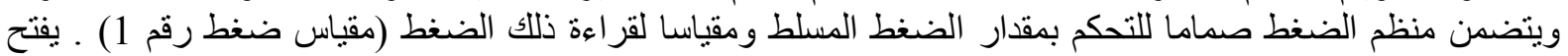

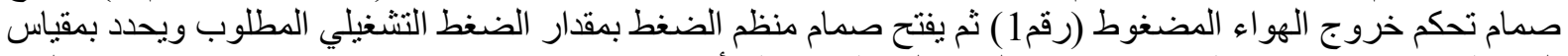

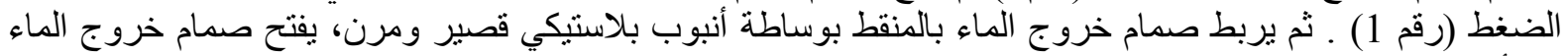

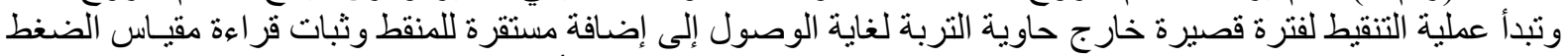

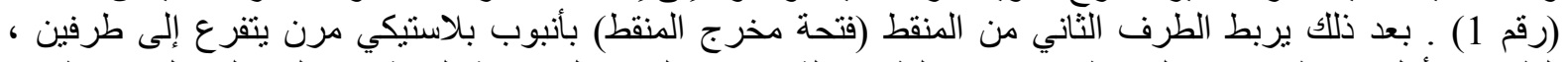

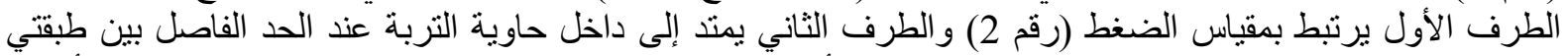

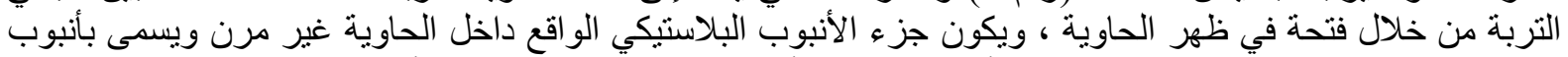

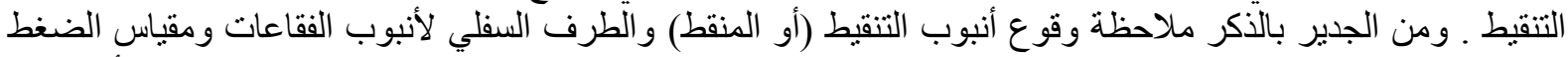

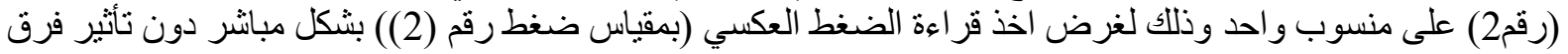

المناسيب على القياس ، ويمكن ملاحظة ذلك في الثكل (2) .

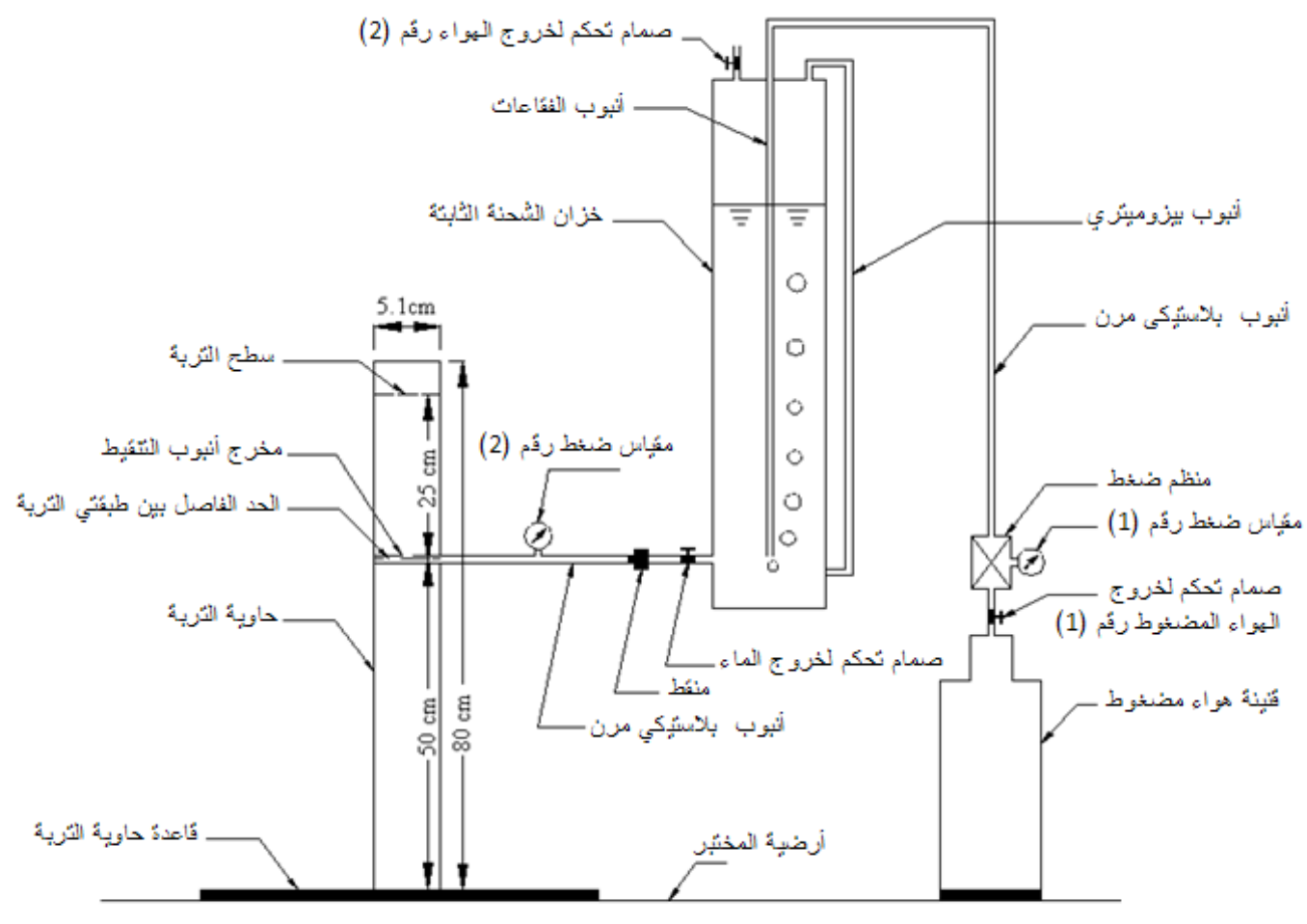

الثكل (2) مخطط عام للأجز اء الرئيسة للجهاز المعتمد .

إن حساب التصريف الفعلي للمنقط تم من خلال معرفة حجم الماء المستهلك من خزان الثحنة الثابتة خلال فترة إضافة الثباء

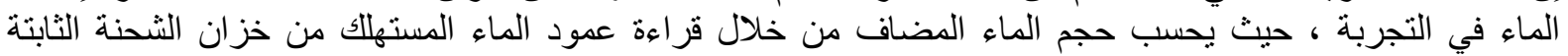


بوساطة مانوميتر مثبت عليه ثم بضرب هذا الارتفاع بمساحة مقطع خزان الثحنة الثابتة ـ تم رص التربة في الحاوية على الثي

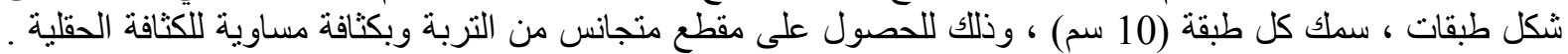

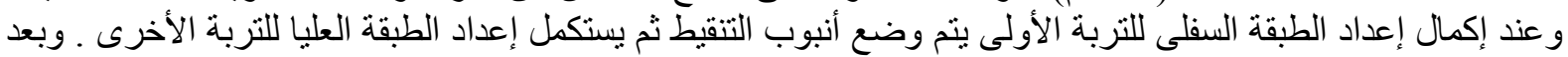

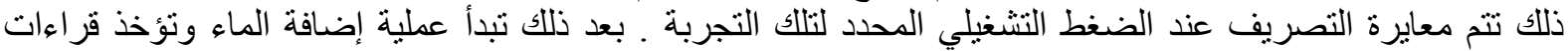

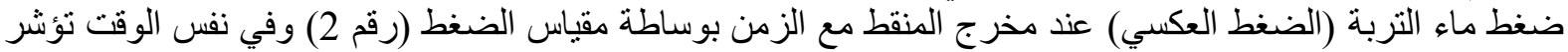

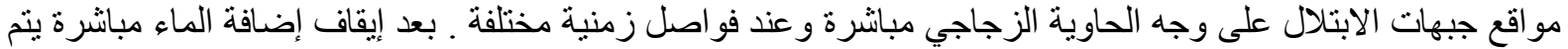

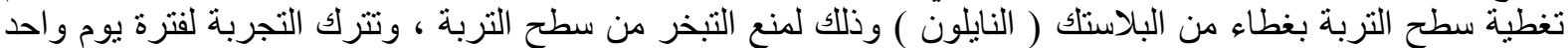

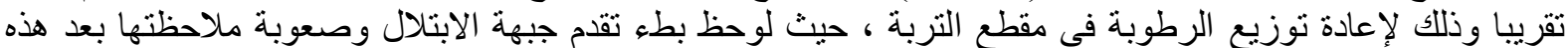

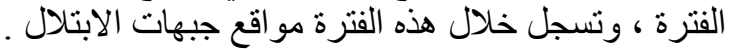

\section{النتائج والمناقشة

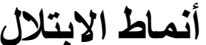

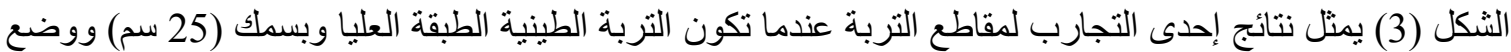

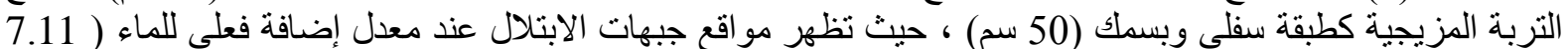

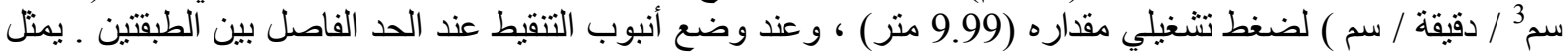

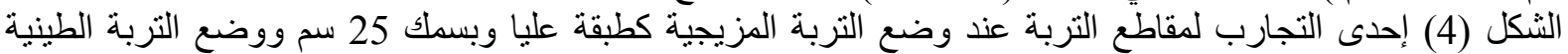

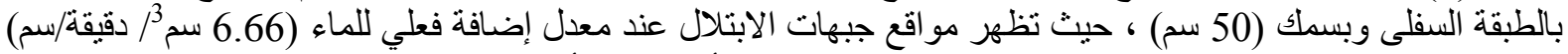

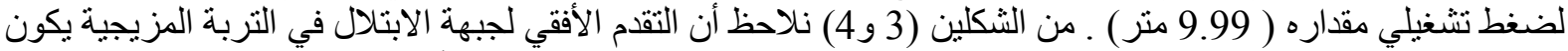

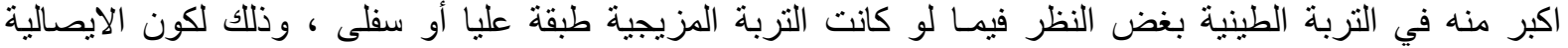

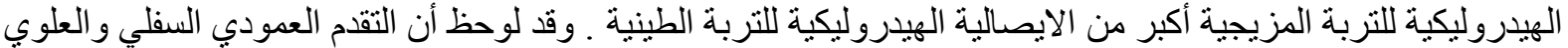

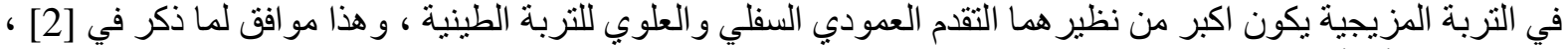

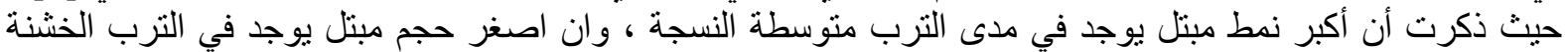
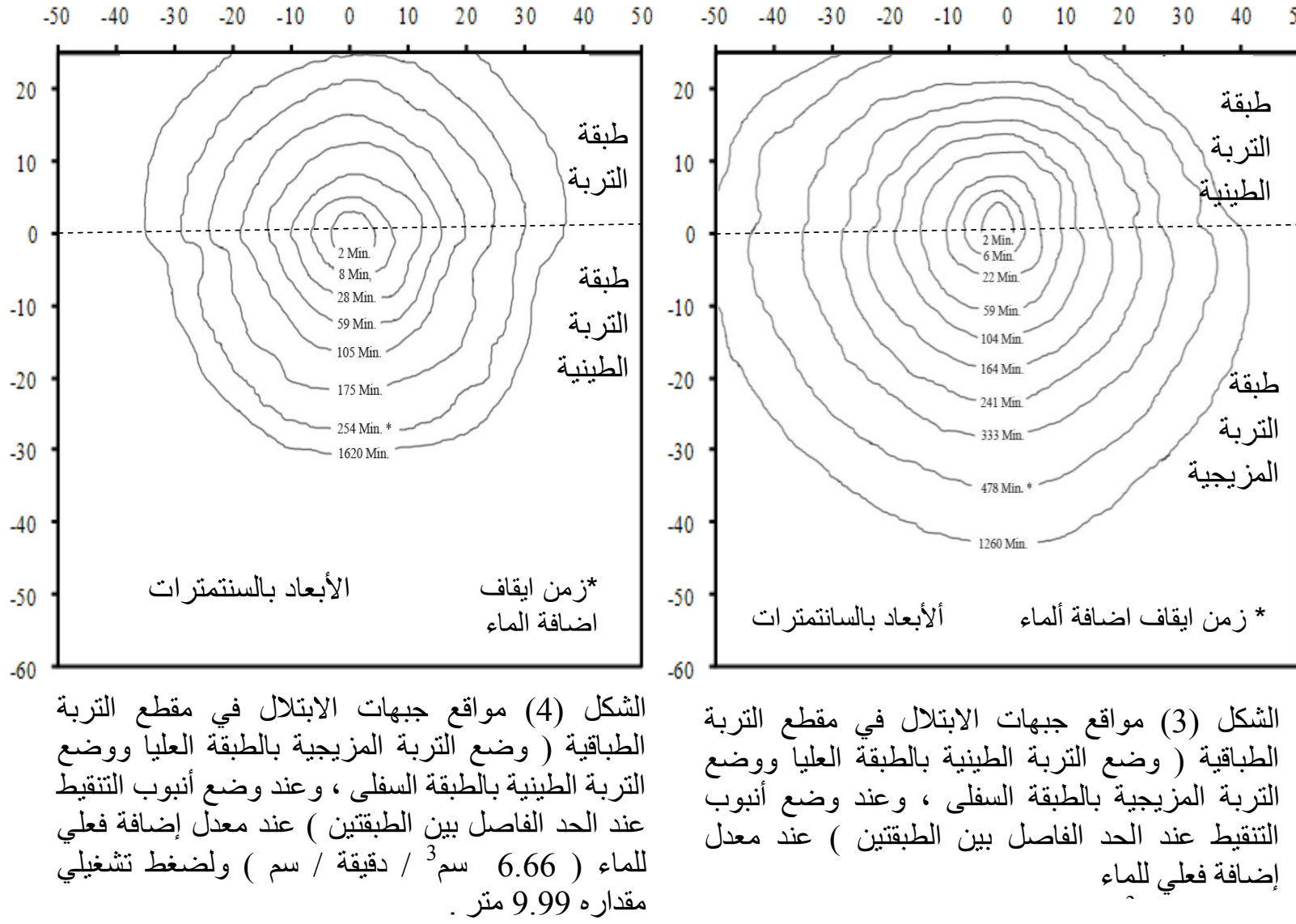
ومن المعلوم أن أحجام المسامات في التربة الطينية تكون اصغر منها في التربة المزيجية وهذا يؤدي إلى صعود الماء

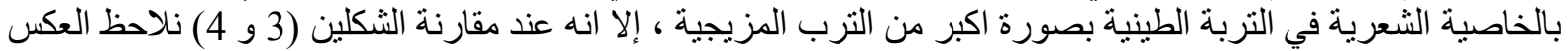

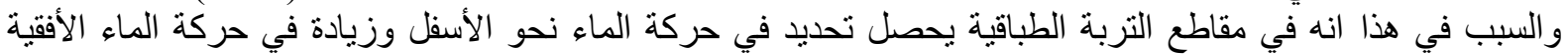

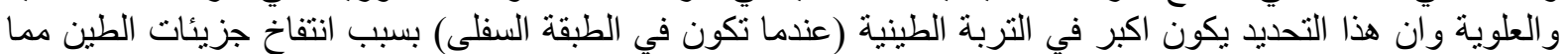

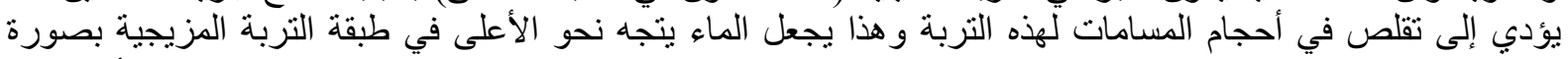
سريعة ، و هذا موافق لما ذكره الباحث [8] ، بالإضافة إلى كون الايصالية الهيدروليكية في التربة المزيجية أعلى من

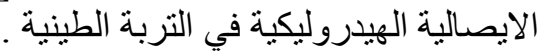
إن در اسة حركة الماء ثثائية البعد ، لمصدر منقة الائط مدفون ، يمكن وصفها هندسيا بمحورين أفقي وعمودي ،حيث إن نقطة

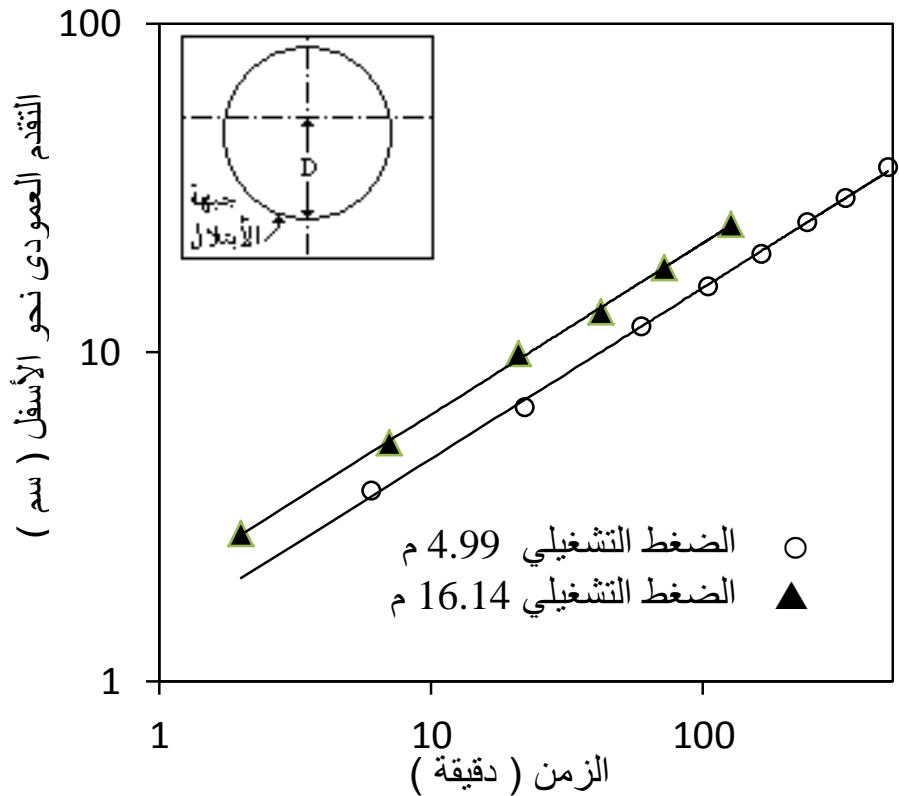

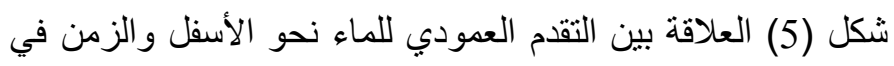

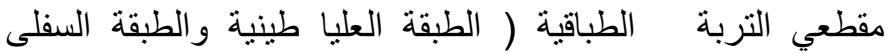

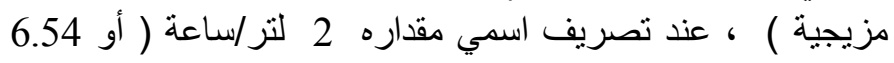

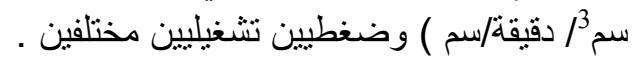

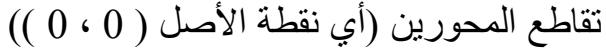
تقع عند المصدر المنقط. يوضح الثكل ( 5 ( ) العلاقة بين التقدام

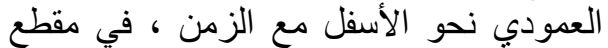

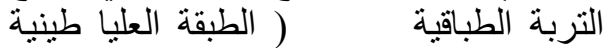

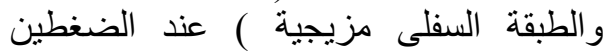

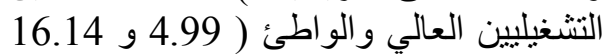

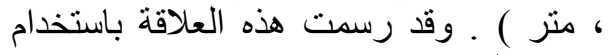

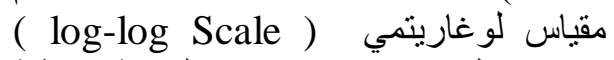
حيث غالبا ما تكون هذئ هذه العلاقة خطية

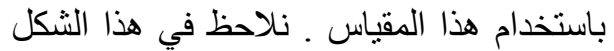
انه عند زيادة قيمة الضغط التشغيلي تزداد

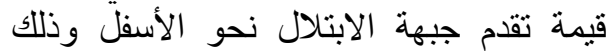

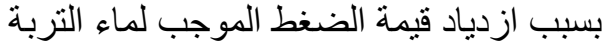

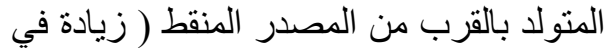

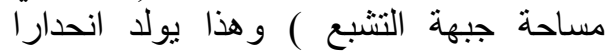
هيدروليكا كبيرا يعمل كقوى محركة للماء التياء

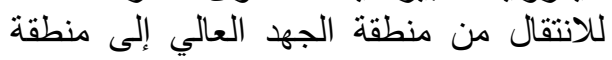

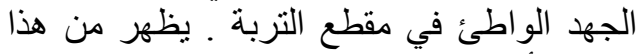
الثكل أن الخطان المستقيمان لمعادلتي التقان التقان يكونان متوازيان تقريبا وان قيمتا الميل آلحسابي لئي

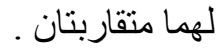

و عليه فأن علاقة التقدم العمودي للماء نحو الأسفل مع الزمن في مقاطع التربة الطباقية خلال الري يمكن تقريبها بالعلاقـــة

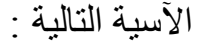

$\mathrm{D}=\mathrm{a}_{1} \mathrm{t}^{\mathrm{b} 1}$

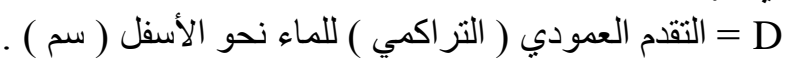

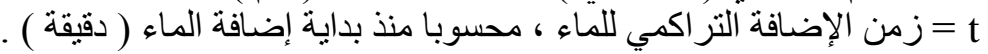

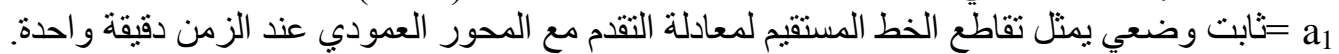
b1 ثابت وضعي يمثل الميل الحسابي للخط المستقيم في معادلة التقام .

و هذا مو افق لما توصل اليه الباحثنان [10] و الباحث [11] من خلال العديد من التجارب المختبرية ، في تمثيل علاقة جبهني

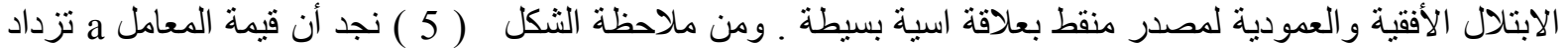

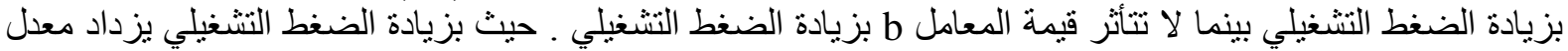

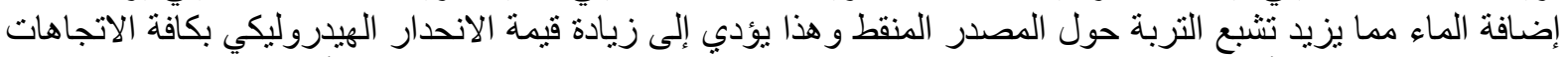

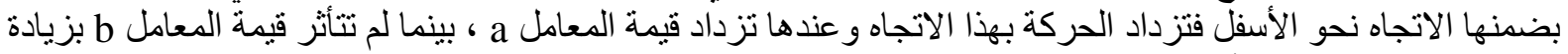

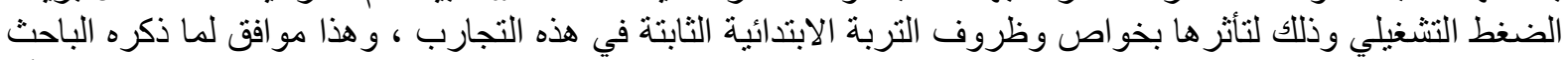

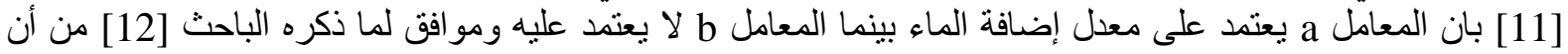
العاملين a و b في المعادلة (2) يعتمدان على نوع التربة و المحتوى الرطوبي الابتدائي لها ـ و عند ملاحظة المعادلة (2) 
نجدها مطابقة لمعادلة كوستاكوف لوصف ارتشاح الماء في التربة وذلك لاعتمادها على نفس العوامل المؤثرة كما جاء في

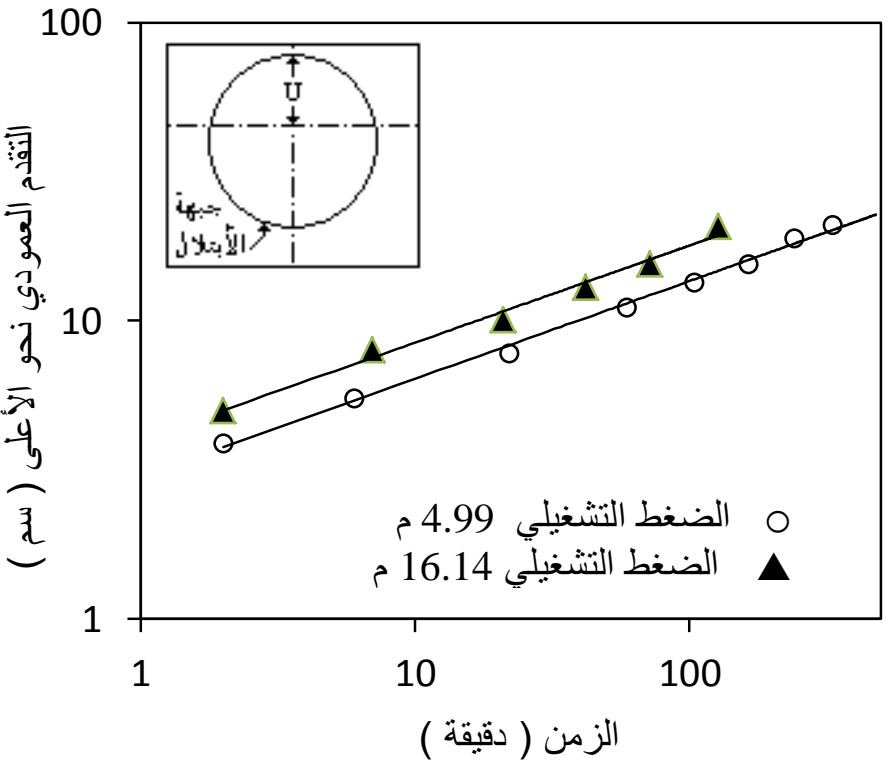

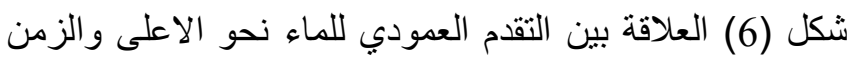

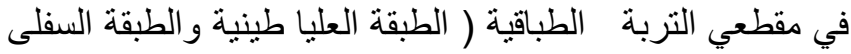

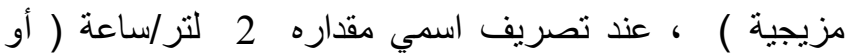

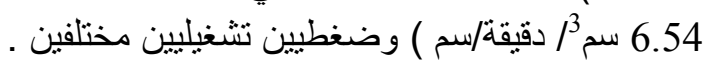

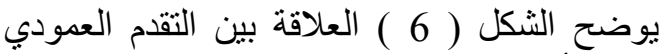

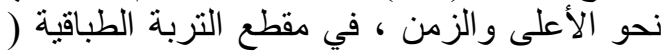

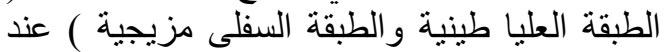

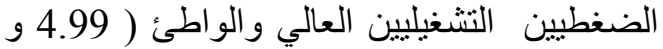
16.14 ، مثر يوضح الثكل ( 7 الزين ) العلاقة بين

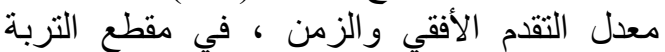

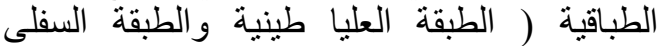

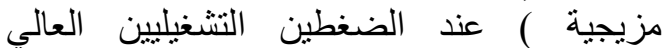

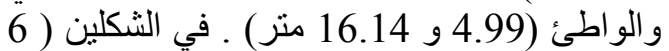

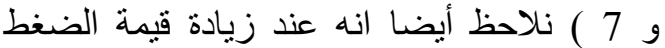

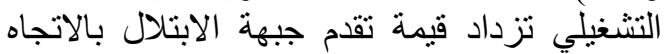

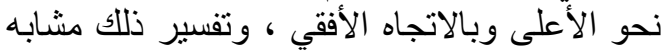

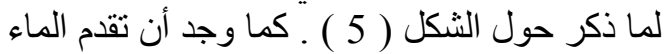

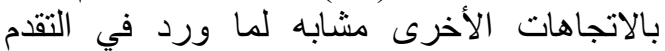

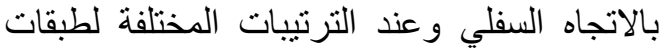
التربة ، ويمكن التعبير عنها بنفس الصيغة الوتلات الواردة في المعادلة (2) وكما يلي :

$\mathrm{H}=\mathrm{a}_{2} \mathrm{t}^{\mathrm{b} 2}$

$\mathrm{U}=\mathrm{a}_{3} \mathrm{t}^{\mathrm{b} 3}$

و H

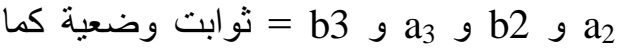

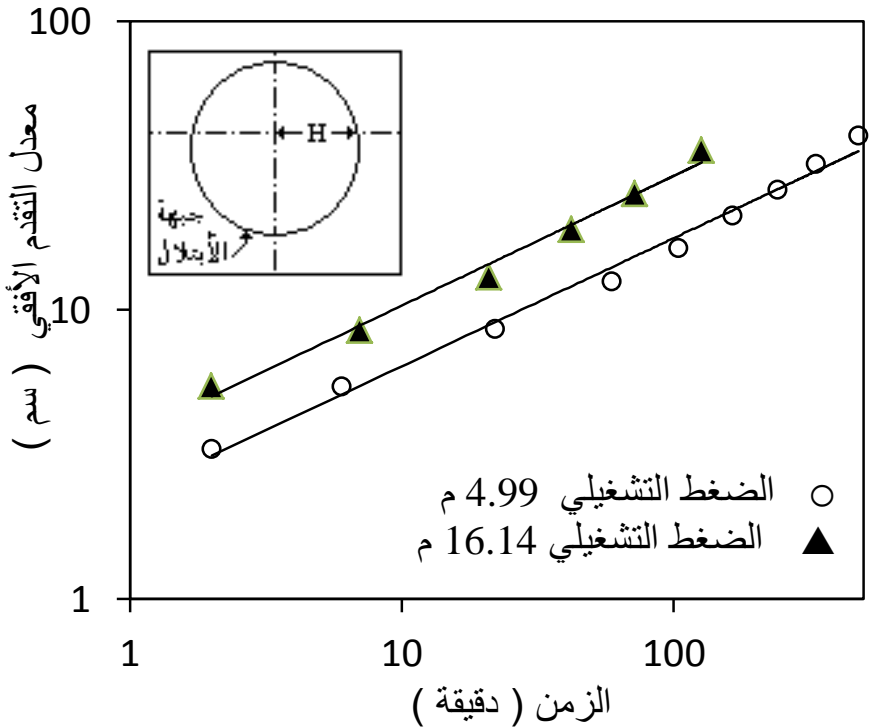

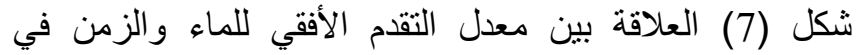
مقطعي التربة الطباقية ( الطبقة العليا طينية والطبقة السفلى لئل

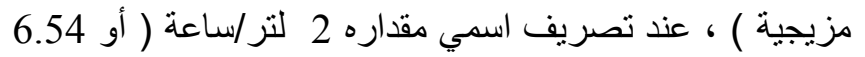
سم/2/ دقيقة/سم ) وضغطيين تشغيليين مختلفين .
جاءت في المعادلة (1) م و

bيبن الجدول (2) قيم الثوابت بالإضافة إلى قيم معامل التحديد (2)

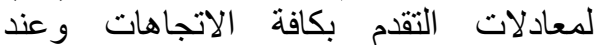
الترتيبات المختلفة لمقاطع التربة و عند ثلاث ضغوط تشغيلية ( 4.99 و 9.99 و 16.14 ونرئ

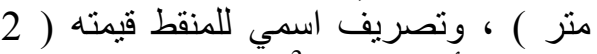
لتر /ساعة أو 6.54 سم 3.5 / دقيقة / سم) .

يلاحظ من الجدول (2) أنه عند مقارنة قيم الجين

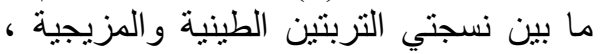

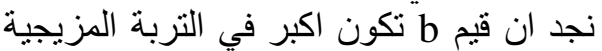

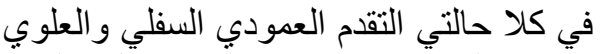
وبغض النظر كونها طبقة عليا او سفلى ولكافة الفية

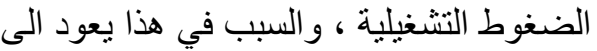
أن الايصالية الهيدروليكية في التربة المزيجية الهينة تكون أعلى منها في التربة الطينية ـ بينما

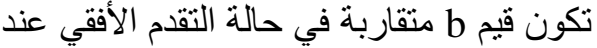

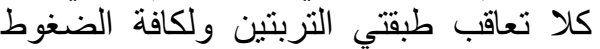
التشغيلية . أما عند مقارنة قيم a ما بين نسجتي

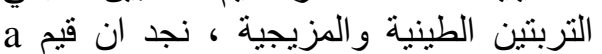


تكون اكبر في التربة الطينية في كلا حالتي التقدم العمودي السفلي والعلوي وبغض النظر كونها طبقة عليا او سفلى ولكافة التها

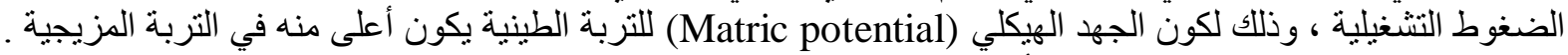
بينما تكون قيم a متقاربة في حالة التقدم الأفقي عند كلا تعاقب طبقتي التربتين ولكافة الضغوط التينة التشغيلية .

جدول ( 2 ) قيم الثوابت الوضعية ( a g b ) ) ومعامل التحديد ( R ) لمقاطع التربة الطباقية عند ضغوط تشغيلية مختلفة

\begin{tabular}{|c|c|c|c|c|c|c|c|c|c|c|}
\hline \multicolumn{9}{|c|}{ الضغط التشغيلي ، م } & \multirow{3}{*}{ اتجاه تقدم } & \multirow{3}{*}{ تعبقات } \\
\hline \multicolumn{3}{|c|}{16.14} & \multicolumn{3}{|c|}{9.99} & \multicolumn{3}{|c|}{4.99} & & \\
\hline $\mathbf{R}^{2}$ & b & $\mathbf{a}$ & $\mathbf{R}^{2}$ & b & $\mathbf{a}$ & $\mathbf{R}^{2}$ & b & $\mathbf{a}$ & & \\
\hline 0.996 & 0.521 & 1.948 & 0.999 & 0.542 & 1.715 & 0.998 & 0.520 & 1.434 & السفلي & طينية عليا \\
\hline 0.987 & 0.449 & 3.680 & 0.996 & 0.421 & 3.053 & 0.990 & 0.442 & 2.307 & الأفقي & مزيجية \\
\hline 0.987 & 0.325 & 3.995 & 0.993 & 0.346 & 3.725 & 0.995 & 0.327 & 3.005 & العلوي & سفلى \\
\hline 0.998 & 0.353 & 3.144 & 0.996 & 0.400 & 2.938 & 0.986 & 0.400 & 2.659 & السفلي & طينية سفلى \\
\hline 0.999 & 0.437 & 3.185 & 0.995 & 0.411 & 3.179 & 0.992 & 0.438 & 2.573 & الأفقي & مزيجية \\
\hline 0.986 & 0.411 & 4.253 & 0.993 & 0.415 & 3.211 & 0.998 & 0.455 & 1.970 & العلوي & \\
\hline
\end{tabular}

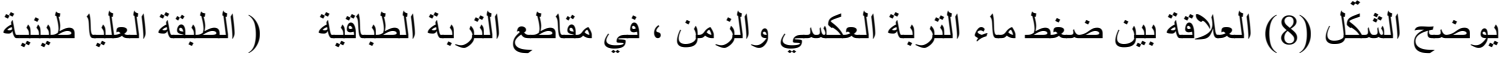

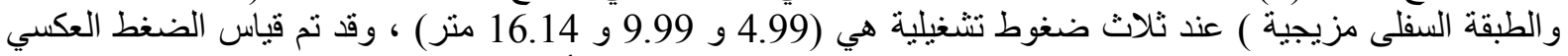

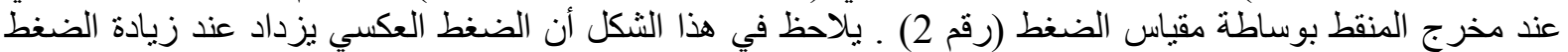

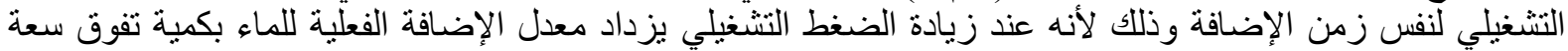

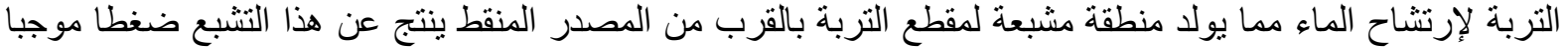

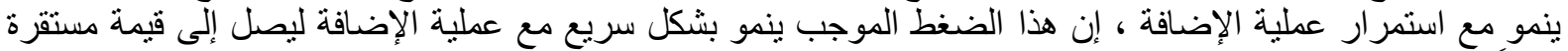

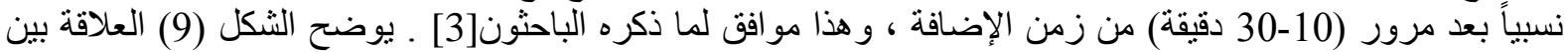

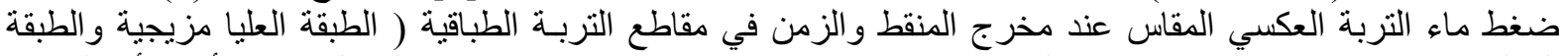

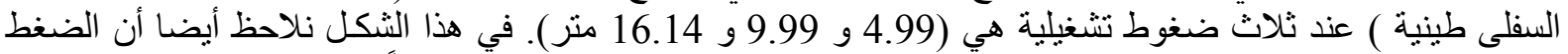

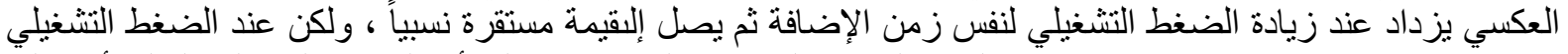

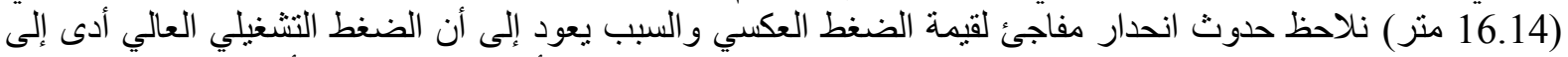

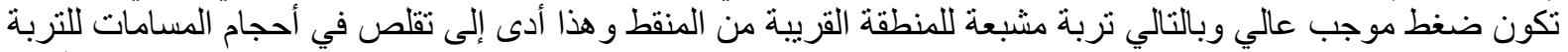

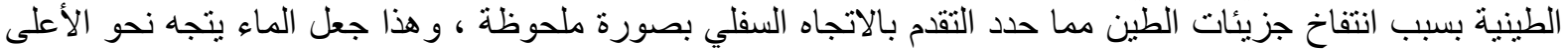

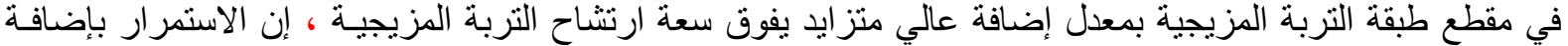

الماء بهذا المعدل العالـي للإضـافـة مع عدم قدرة التربة التية

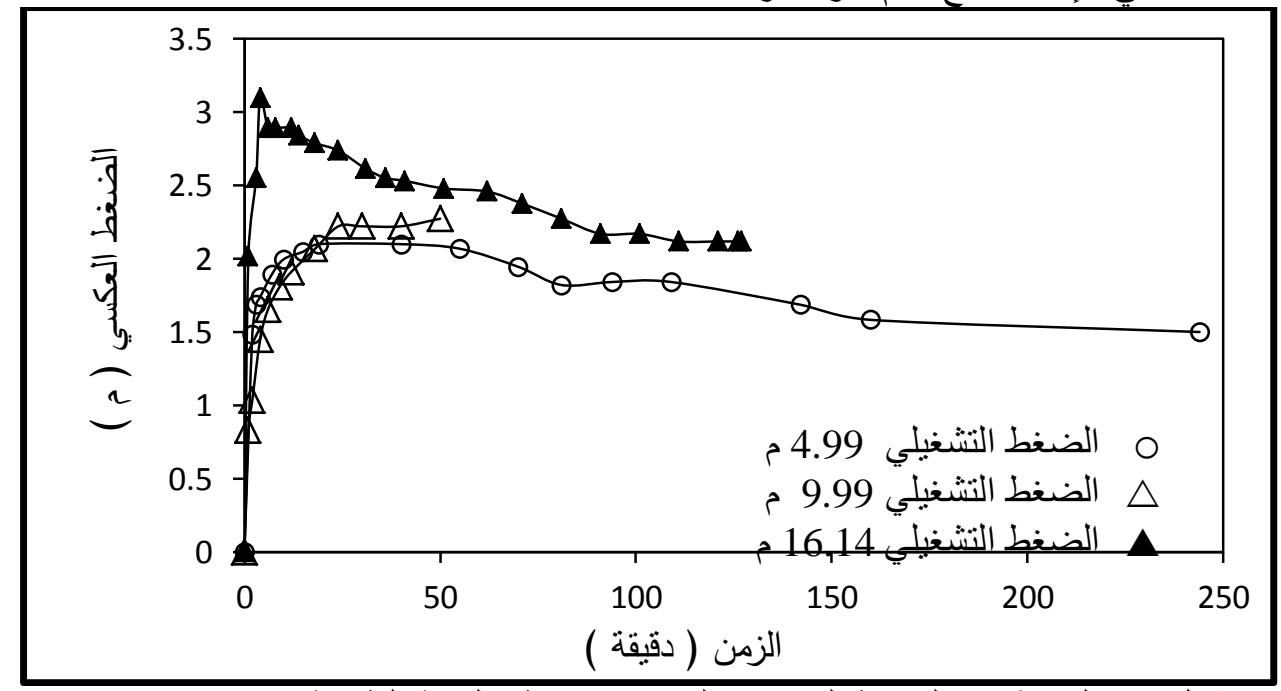

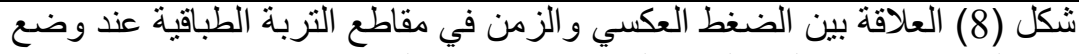

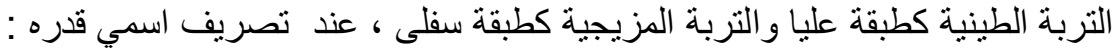

2 لنر /ساعة و عند ضغو ط تشغيلية مختلفة 


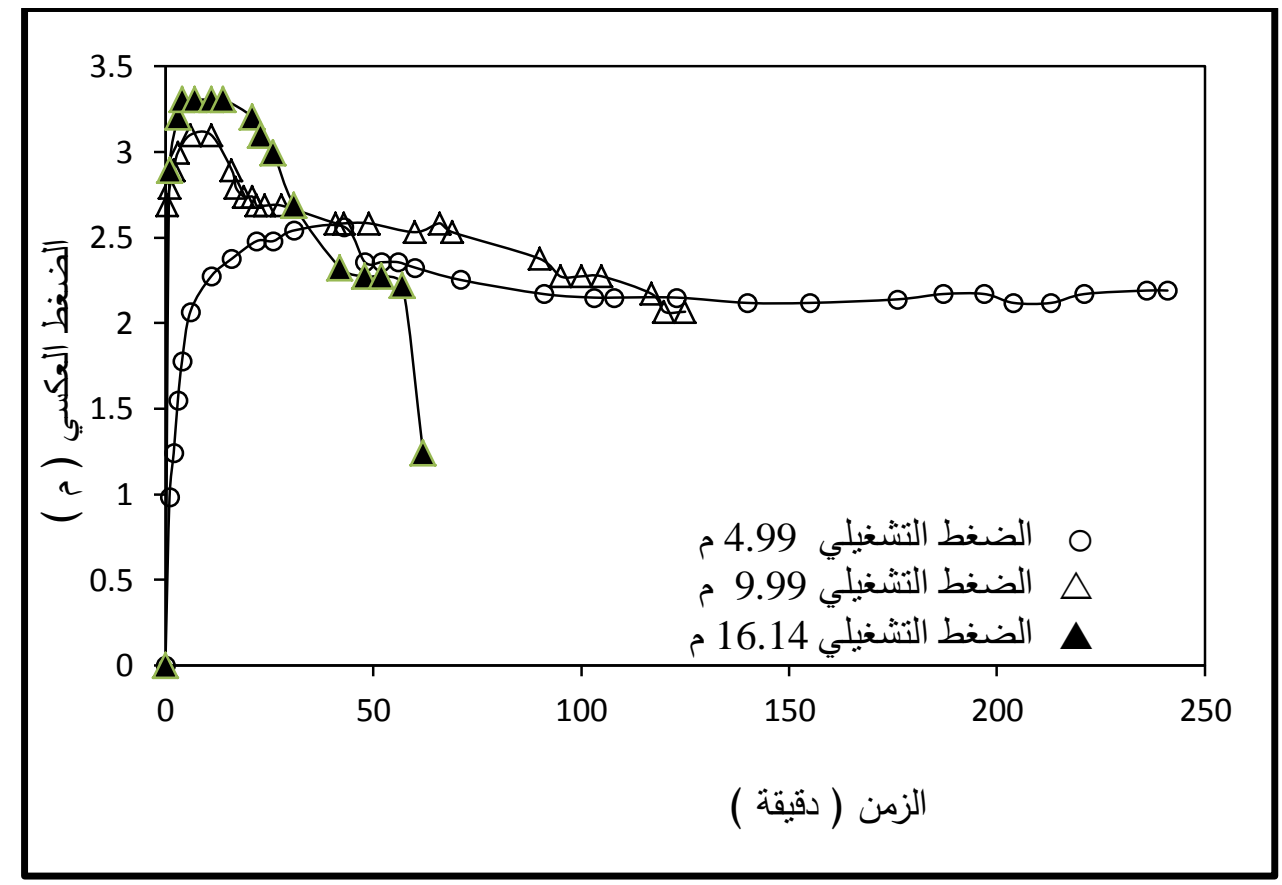

شكل (9) العلاقة بين الضغط العكسي الزمن في مقاطع التربة الطباقية عند وضع التربع

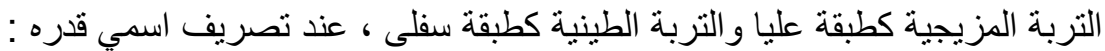

2 لتر /ساعة وعند ضغوط تشغيلية مختلفة .

المزيجية على استيعاب هذه الكمية من الماء ونشر ها خلال مقطع التربة أدى إلى تشكل فجوة مائية قرب المصدر المنقط

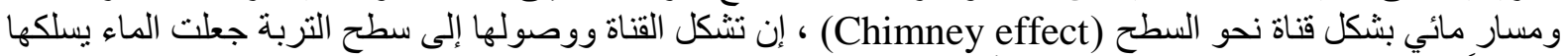

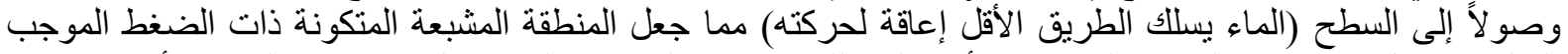

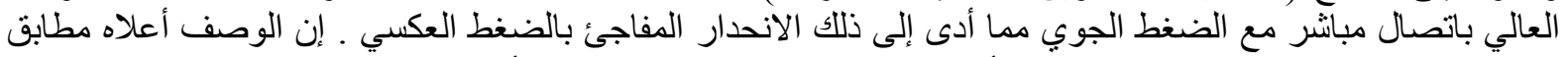

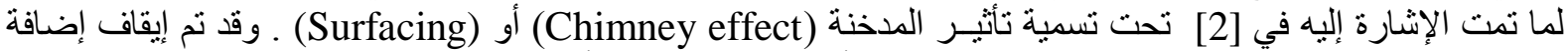
الماء عند بدء خروج الماء الى سطح التربة بما يعرف بتأثير المدخنة لمنع التأثير على النتائج ـ من مقارنة الثنكلين ( 8 و 9

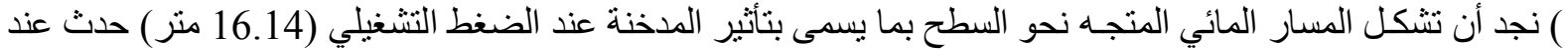

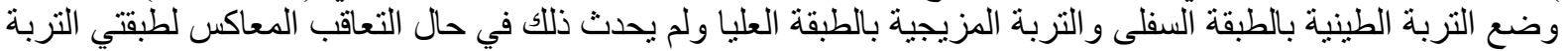

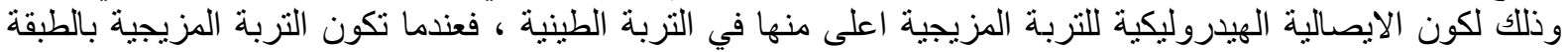

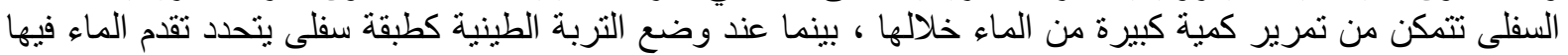

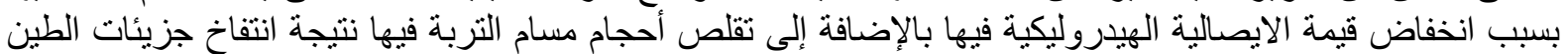

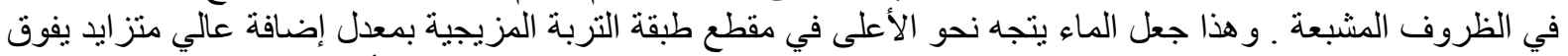

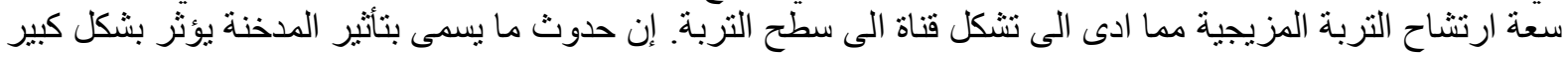

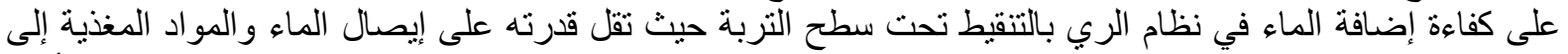

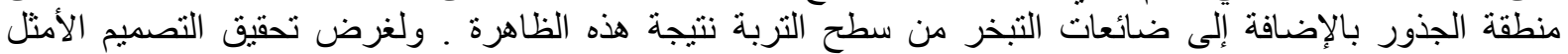

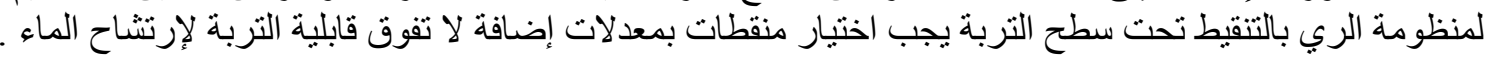

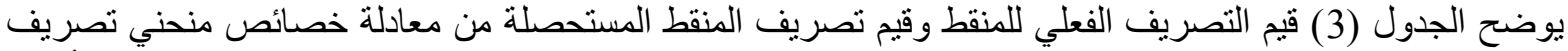

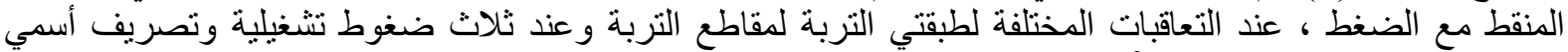

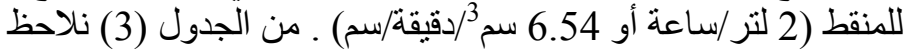


جدول (3) قيم تصاريف المنقط الفعلية (في التربة) وتصاريف المنقط من معادلة منحني خصائص المنقط (خارج التربة) .

\begin{tabular}{|c|c|c|c|c|}
\hline الفقلي / تصريف المنقط & تصرف المنقط & سمن المعاديفة المنقط & التشغيلي & تعاقب طبقات التربة \\
\hline 0.72 & 3.68 & 5.12 & 4.49 & زيجية سفلى \\
\hline 0.73 & 3.71 & 5.12 & 4.49 & طينية سفلى مزيجية عليا \\
\hline 0.90 & 7.11 & 7.89 & 9.99 & طينية عليا مزيجية سفلى \\
\hline 0.84 & 6.66 & 7.89 & 9.99 & طينية سفلى مزيجية عليا \\
\hline 0.89 & 9.09 & 10.23 & 16.14 & طينية عليا مزيجية سفلى \\
\hline 0.88 & 9.05 & 10.23 & 16.14 & طينية سفلى مزيجية عليا \\
\hline
\end{tabular}

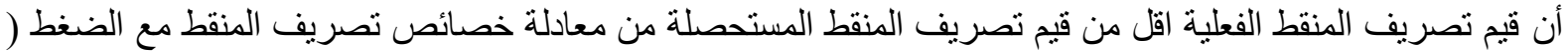

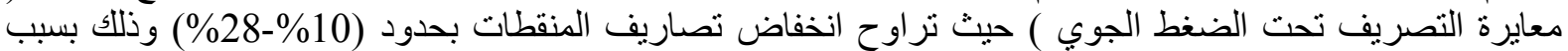

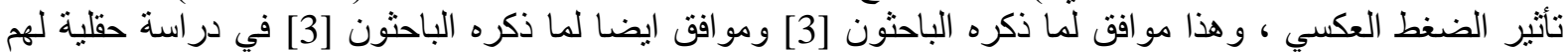

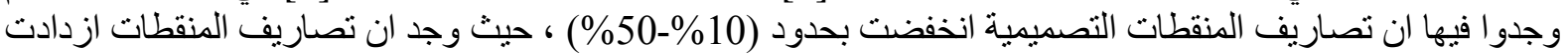

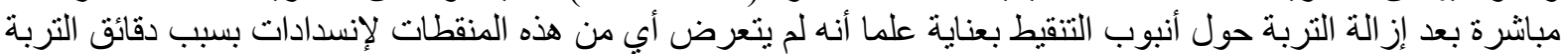

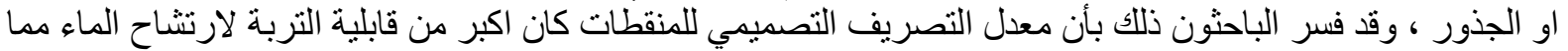

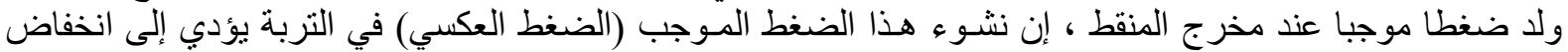

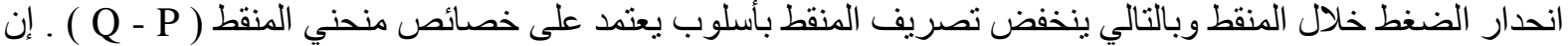

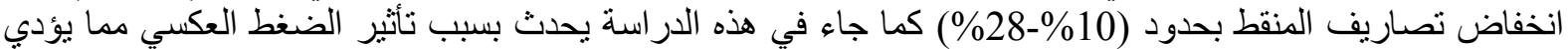

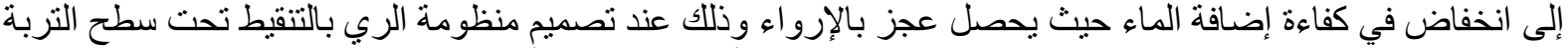

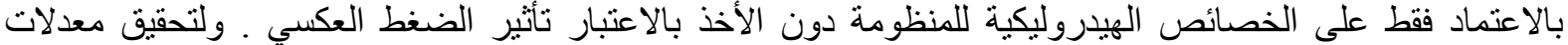

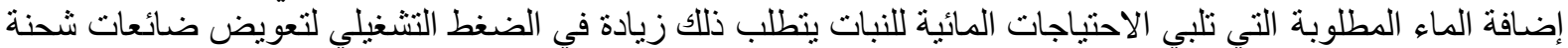

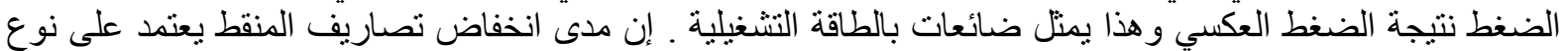

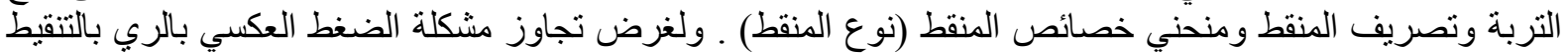

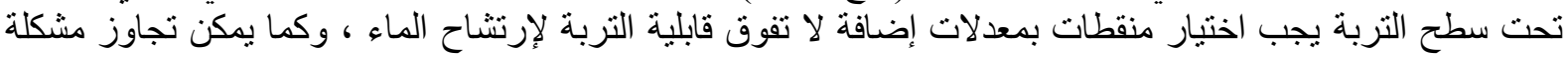

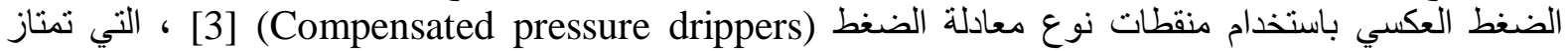

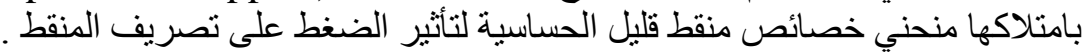

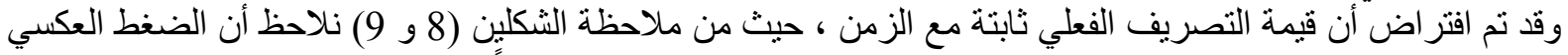

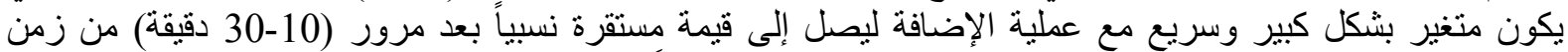
الإضافة ، وبهذا يصل انحدار الضغط داخل المنقط إلى قيمة ثابتة نسبياً بعد مرور هذه الفئة الفترة و وعليه يمكن اعتبار تصريف

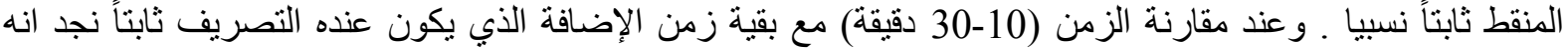

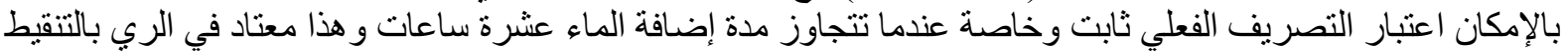

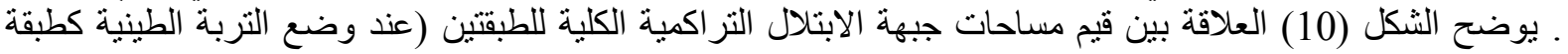

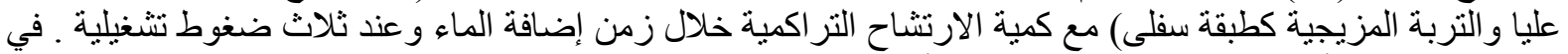

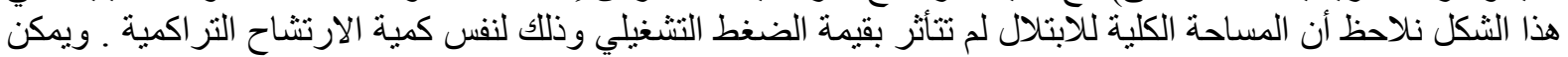

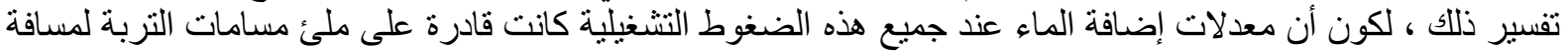

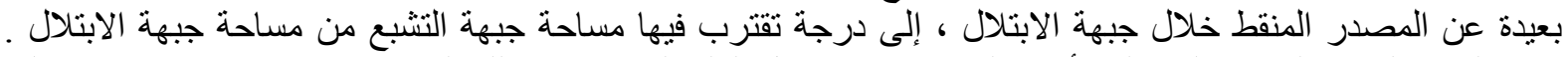

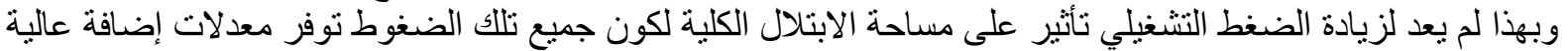

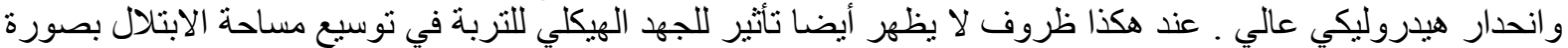
ملحوظة حيث يصبح امتداد مساحة الابتلال تحت هذه الظروف محكوما بمعدلات الإضافة العالية كما ورد في أعلاه . 


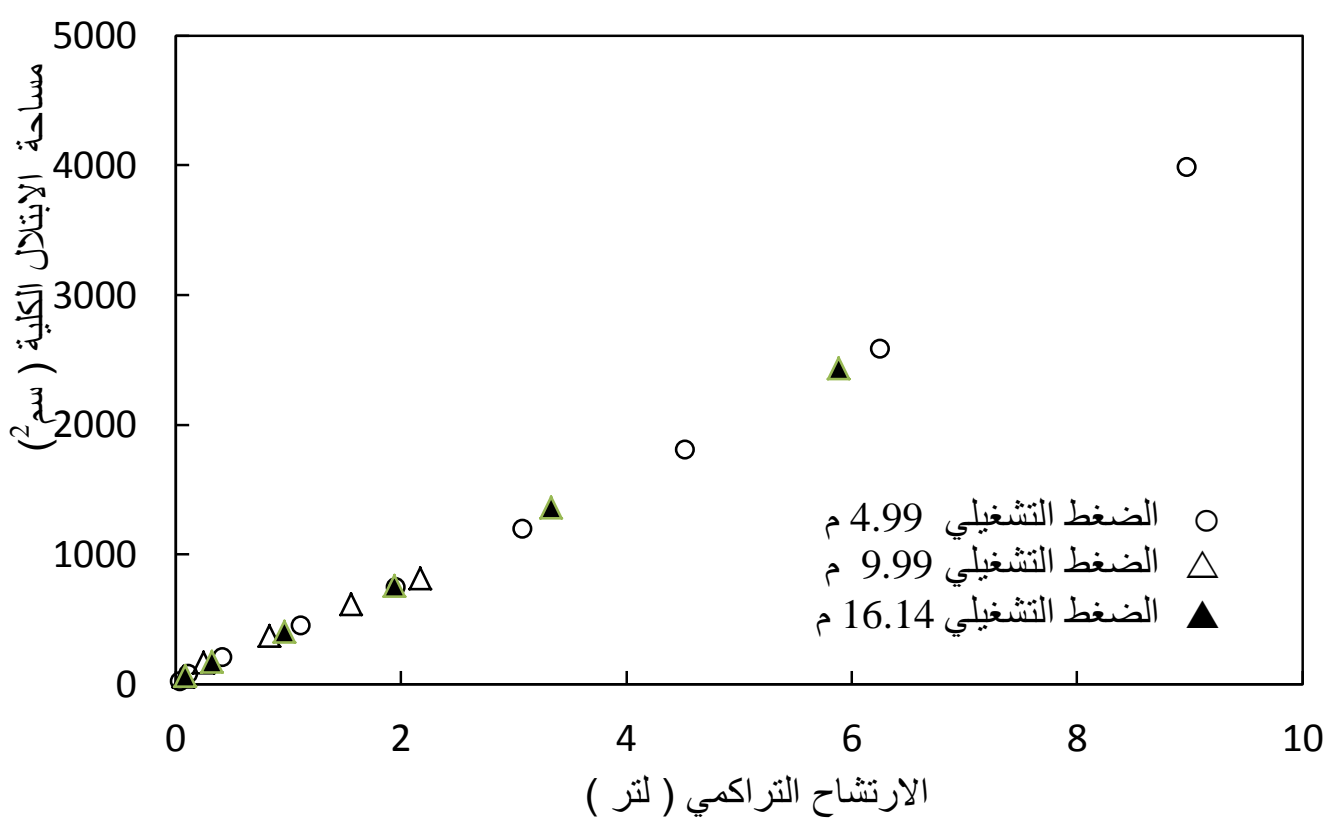

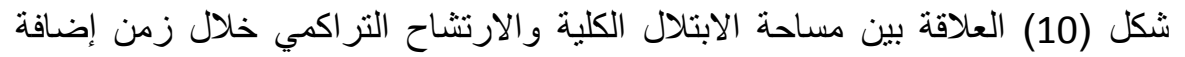

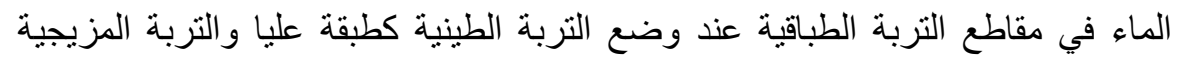

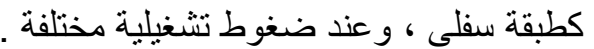

أظهرت الدراسة أن معدل تقدم الابتلال من مصدر منقط تحت سطح التربة عند أي زمن يمكن تقريبه بعلاقة أسية

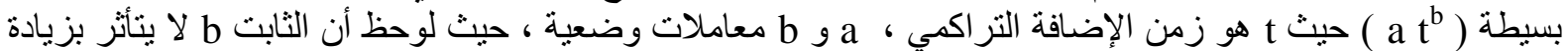

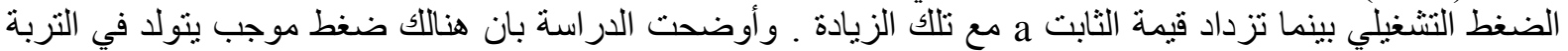

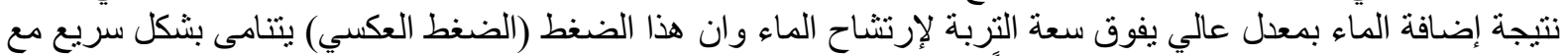

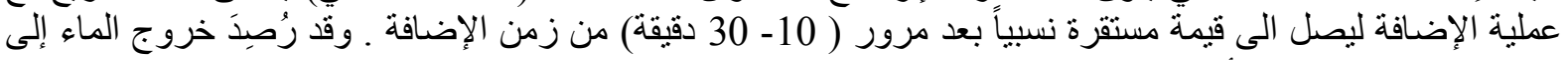

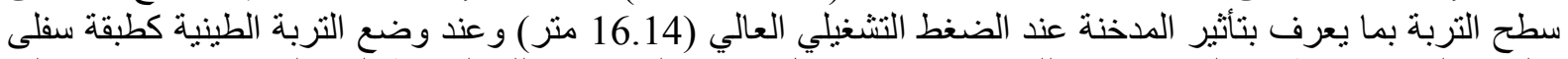

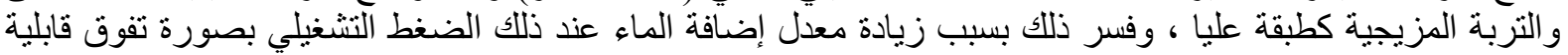

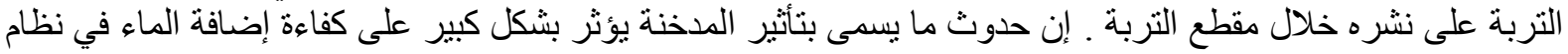

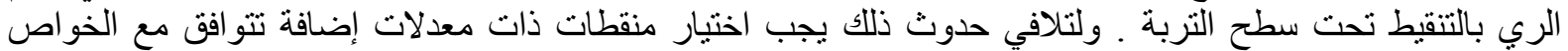

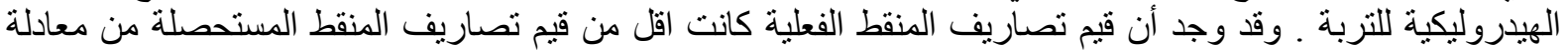

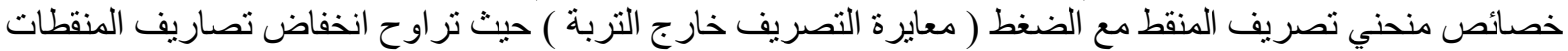

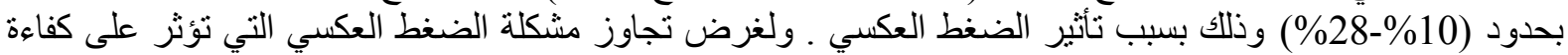

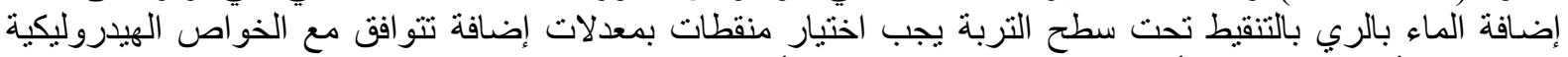

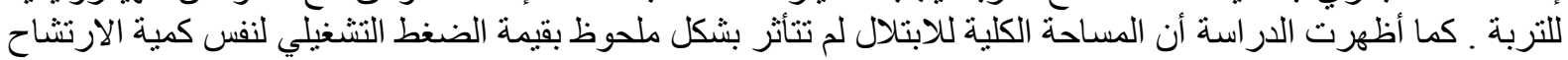
التر اكمية .

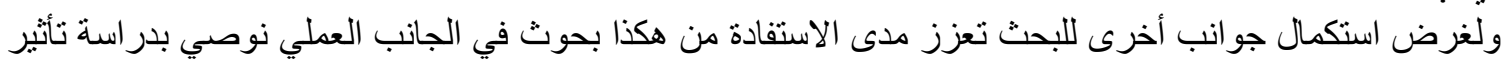

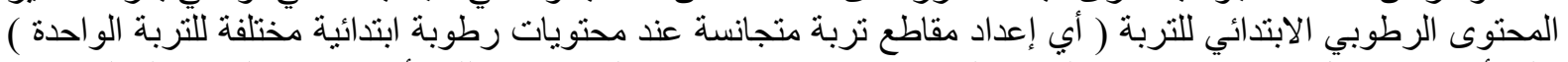

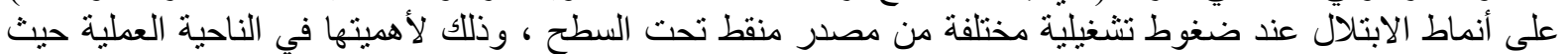

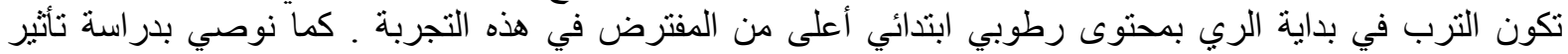

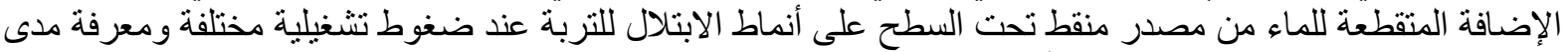
ذلك في تقليل مشاكل الضغط العكسي ونأثنير المدخنة . 
1.Camp, C.R. ( 1998 ) . "Subsurface Drip Irrigation : A Review" Transactions of the American Society of Agricultural Engineers, Vol. 41 , No.5 , pp. 1353-1367 .

2. Washington State Department of Health ( 2007 ). "Recommended Standards and Guidance for Performance, Application, Design and Operation and Maintenance Subsurface Drip Systems" Personal communication , http://www.doh.wa.gov/ehp/ts/ww/Drip_8-29-07.pdf

3. Shani, U., S . Xue , R. Gordin - Katz, and A . W . Warrick ( 1996 ) . "Soil Limiting Flow from Subsurface Emitter. I : Pressure Measurements" Journal of Irrigation and Drainage Engineering, Vol.122, No.5, pp. 291-295 .

4. Ben-Gal, A., N . Lazorovitch , and U . shani ( 2004 ). " Subsurface drip irrigation in gravel-filled cavities" Vadose zone journal vol.3 , November , pp 1407-1413 .

5. Siyal, A.A., and T.H. Skaggs ( 2009 ) . "Measured and simulated soil wetting patterns under porous clay pipe sub-surface irrigation" Agricultural water management , $96, \mathrm{pp}$ 893-904.

6. Yao, W. W., F. Y. Ma , J. Li , and M. Parkes ( 2011 ). "Simulation of point source wetting pattern of subsurface drip irrigation" Irrigation Science, 29, pp. 331-339 .

7. Avi, S ., and G. Sinai ( 2004) . "Application of conditioner solution by subsurface emitters for stabilizing the surrounding soil" Journal of irrigation and drainage engineering, Vol. 130 , No. 6 , pp. 485-490 .

8. Jiusheng, Li., and H. Ji ( 2007 ) . "Wetting Patterns and Nitrate Distributions in Layered Soils from a Surface Point Source" Agricultural Sciences in china, Vol.6, Issue 8 , August, pp.970-980 .

9.Gee , G . W ., and J . W . Bauder ( 1986 ). "Particle Size Analysis in Methods of Soil Analysis" Part 1 : Physical and Mineralogical Methods ( $2^{\text {nd }}$ edition ), edited by Klute ., Am. Soc. Agron. Madison, WI. pp. 383-411.

10. Keller J, Bliesner RD (1990). "Sprinkle and trickle irrigation" Avi Book

Pub. Van Nostrand Reinhold, New York.

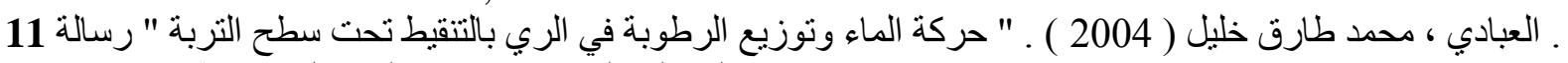

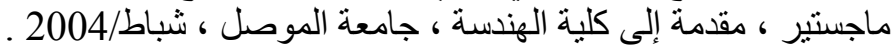

12. Ghosh, R . K . ( 1980 ) . "Modeling Infiltration” Soil Sc., Vol. 130 , No. , 6 , PP. 297 302 . 